\title{
Characterization of Heat Waves in the Sahel and Associated Physical Mechanisms
}

\author{
BOUTHEINA OUESLATI AND BENJAMIN POHL \\ Centre de Recherche de Climatologie, UMR 6282 Biogéosciences, CNRS/Université de Bourgogne \\ Franche-Comté, Dijon, France \\ VINCENT MORON \\ Université Aix-Marseille, UM 34 CNRS, CEREGE, Aix-en-Provence, France, and \\ Columbia University, Palisades, New York \\ SANDRA ROME \\ Université Grenoble Alpes, LTHE UMR 5564, Grenoble, France \\ SERGE JANICOT \\ LOCEAN, Sorbonne Universités UPMC-IRD-MNHN, UMR 7159, Paris, France
}

(Manuscript received 3 June 2016, in final form 3 January 2017)

\begin{abstract}
Great effort is made to address heat waves (HWs) in developed countries because of their devastating impacts on society, economy, and environment. However, HWs are still understudied over developing countries. This is particularly true in West Africa, and especially in the Sahel, where temperatures recurrently reach critical values, such as during the $2010 \mathrm{HW}$ event in the western Sahel. This work aims at characterizing the Sahelian HWs during boreal spring seasons (April-May-June) and understanding the mechanisms associated with such extreme events. Over the last three decades, Sahelian HWs have been becoming more frequent, lasting longer, covering larger areas, and reaching higher intensities. The physical mechanisms associated with HWs are examined to assess the respective roles of atmospheric dynamics and radiative and turbulent fluxes by analyzing the surface energy budget. Results suggest that the greenhouse effect of water vapor is the main driver of HWs in the western Sahel, increasing minimum temperatures by enhanced downward longwave radiation. Atmospheric circulation plays an important role in sustaining these warm anomalies by advecting moisture from the Atlantic Ocean and the Guinean coasts into the Sahel. Maximum temperature anomalies are mostly explained by increased downward shortwave radiation due to a reduction in cloud cover. Interannual variability of HWs is affected by the delayed impact of El Niño-Southern Oscillation (ENSO), with anomalous temperature warming following warm ENSO events, resulting from an amplified water vapor feedback.
\end{abstract}

\section{Introduction}

Heat waves (HWs) are periods of extremely high temperature that can have dramatic consequences on society, the economy, and the environment at the global and regional scale. In response to global warming, temperature extremes will become more frequent and have higher intensity and duration (Meehl and Tebaldi

Corresponding author e-mail: Boutheina Oueslati, oueslati@ lsce.ipsl.fr
2004; Kharin et al. 2013; Collins et al. 2013), consistent with their observed evolution over the past decades (Donat et al. 2013). Documenting HW characteristics and understanding the associated physical mechanisms are highly needed to build reliable predictions and develop adequate mitigation and adaptation strategies. Great effort has been made to investigate HWs in developed countries since 2003, just after the European dramatic event (Schär and Jendritzky 2004; GarcíaHerrera et al. 2010). However, HWs are still understudied in developing countries and especially in West 
Africa where mean climate is warmer and adaptation capacities are relatively low.

Previous studies (Fontaine et al. 2013; Moron et al. 2016; Russo et al. 2016) have investigated the time evolution of temperature over the past decades in West Africa and show strong positive trends of maximum and minimum temperature, associated with more frequent warm temperatures (exceeding the 90th percentile) as well as higher frequencies and longer durations of HWs. These positive trends of maximum and minimum temperatures and warm extremes are also predicted by climate projections over the twentyfirst century and are larger in arid and semiarid regions, and especially in West Africa, than at the global scales (Collins et al. 2013; Roehrig et al. 2013; Russo et al. 2016).

The physical mechanisms and feedbacks associated with HWs are widely addressed in the midlatitudes (Seneviratne et al. 2012). The atmospheric circulation plays an important role in increasing temperature extremes. Indeed, HWs in Europe are mostly associated with anticyclonic circulation anomalies that produce subsidence, clear skies, warm air advection from the eastern subtropical Atlantic and Africa, and prolonged hot conditions at the surface (Van Oldenborgh 2007; Cattiaux et al. 2009). Temperature extremes are also amplified by local thermodynamical mechanisms including soil moisture deficit (Fischer et al. 2007; Fischer and Schär 2009), water vapor feedback (Shongwe et al. 2011), and cloud processes (Tang et al. 2012; Boé and Terray 2014). In contrast with midlatitudes, still little is known about the physical processes controlling warm temperature anomalies in the Sahel. Fontaine et al. (2013) documented the atmospheric patterns associated with HWs in West Africa and proposed a mechanism by which a Rossby wave causes midtropospheric subsidence and anticyclonic rotation over the continent, favoring anomalous heating in spring season. Moron et al. (2016) documented the temporal variations of warm extremes in West Africa and their relationships with remote regions. It is emphasized that the lowfrequency (LF) variations are at least the signature of the global warming and that the high-frequency (HF) variations are dominated by the delayed impact of $\mathrm{El}$ Niño-Southern Oscillation (ENSO) events over the region, with warm temperature anomalies tending to follow warm ENSO events.

The purpose of this study is to enlarge our knowledge of HWs in the Sahel from synoptic observations and reanalysis and identify the main physical drivers of warm extremes. We investigate the role of atmospheric circulation, turbulent and radiative fluxes, and their sensitivity to water vapor and clouds. The paper is structured as follows. Section 2 presents the datasets used in the study and the HW definition retained for the Sahel. Section 3 describes the HW characteristics in terms of frequency, duration, intensity, and spatial extent. Sections 4 and 5 investigate the physical processes controlling warm temperature anomalies, focusing first on the spring 2010 case study and then on the interannual time scales. Section 6 summarizes the main results.

\section{Data and heat wave definition}

\section{a. Data description}

The global summary of the day (GSOD) synoptic observations (Moron et al. 2016) and the European Centre for Medium-Range Weather Forecasts (ECMWF) interim reanalysis (ERA-Interim, hereafter ERA-I) (Dee et al. 2011) are used for this study. GSOD dataset provides daily maximum temperature (Tmax), minimum temperature (Tmin), and mean dewpoint temperatures, available from 1942 over the West African domain represented in Fig. 1. The quality of GSOD data has been assessed following Moron et al. (2016); the spatial coherence of temperature anomalies was checked and spurious values were removed. ERA-I is available from 1979 and provides 6-h forecasts and analysis of state variables (temperature, winds, and humidity) at T255 spectral resolution $(\simeq 75 \mathrm{~km})$ and on 60 vertical levels from the surface up to $0.1 \mathrm{hPa}$. ERA-I also provides accumulated fluxes over the forecast period, including surface and top-of-the-atmosphere (TOA) radiative fluxes, as well as latent and sensible heat fluxes at the surface. The 1979-2014 common period between GSOD and ERA-I is chosen for the study. The western Sahel $\left(10^{\circ}-\right.$ $17^{\circ} \mathrm{N}, 15^{\circ} \mathrm{W}-15^{\circ} \mathrm{E}$; rectangular area in Fig. 1) is investigated. This region is chosen because it presents the largest number of HW days over the West African domain (Vizy and Cook 2012; S. Rome et al. 2016, unpublished manuscript; Moron et al. 2016) and it is homogeneously covered by GSOD stations (Fig. 1). Only stations having at least $50 \%$ of available daily entries are retained, corresponding to a total of 48 stations. On average, over this domain, $19 \%$ of daily Tmax and Tmin are missing.

\section{b. Heat wave definition}

There is no universal definition of an HW event since it is highly dependent on the sector (human health, agriculture, transport, and so forth) and region of interest. HWs can be defined from daily meteorological variables such as Tmax and Tmin (e.g., Beniston et al. 2007) or from heat stress indices (e.g., Fischer and Schär 2010) that account for HW health impacts on humans. In our case, we choose the heat index, which 


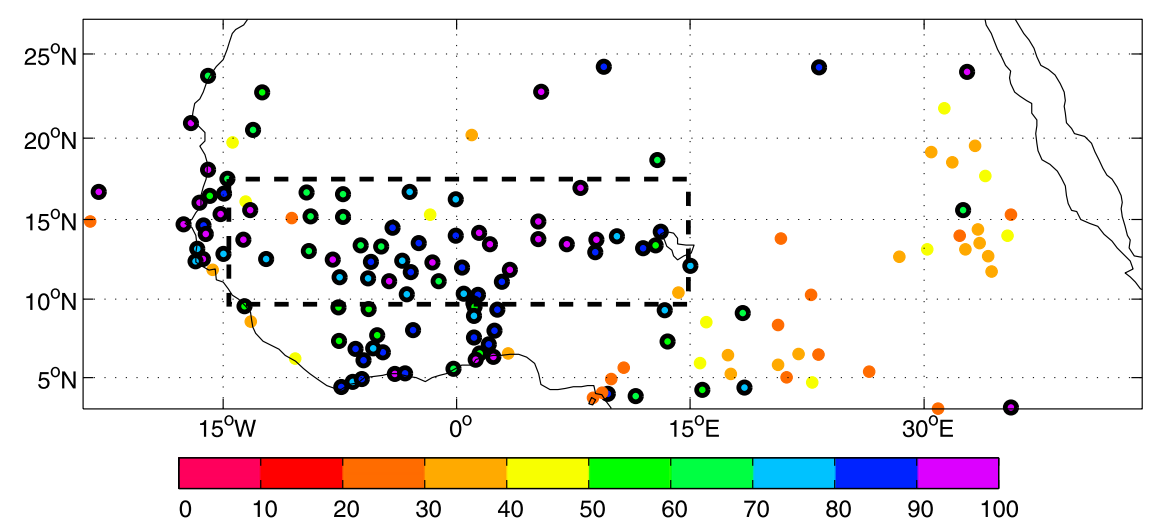

FIG. 1. Daily availability of Tmax over 1979-2014 for GSOD stations. The region of the West African domain investigated in this study is enclosed within the dashed rectangular box. For ERA-I, regional-scale means are made on the grid points belonging to the domain. Stations having at least $50 \%$ of available daily entries are marked by a black circle.

is a nonlinear function of temperature $T$ and relative humidity $(\mathrm{RH})$ that determines the human-perceived equivalent temperature (Steadman 1979). High relative humidity limits, in fact, human thermoregulation by evaporative cooling, therefore amplifying the heat stress of temperature extremes. Climatic conditions become dangerous for human health (high risk of heat stroke and muscle cramps) for a heat index (HI) larger than $40^{\circ} \mathrm{C}$ and extremely dangerous for $\mathrm{HI}$ larger than $54^{\circ} \mathrm{C}$. HI is computed for temperatures larger than $26.6^{\circ} \mathrm{C}\left(80^{\circ} \mathrm{F}\right)$, following the U.S. National Weather Service $\mathrm{HI}$ chart ${ }^{1}$ and is defined as follows:

$$
\begin{aligned}
\mathrm{HI}= & -42.37+2.04 T+10.14 \mathrm{RH}-0.22 \mathrm{TRH}-6.83 \\
& \times 10^{-3} T^{2}-5.48 \times 10^{-2} \mathrm{RH}^{2}+1.22 \times 10^{-3} T^{2} \mathrm{RH} \\
& +8.52 \times 10^{-4} T \mathrm{RH}^{2}-1.99 \times 10^{-6} T^{2} \mathrm{RH}^{2},
\end{aligned}
$$

where $T$ and $\mathrm{HI}$ are expressed in ${ }^{\circ} \mathrm{F}$. The obtained $\mathrm{HI}$ is then expressed in ${ }^{\circ} \mathrm{C}$ throughout the paper.

In this study, an HW is defined as a spell of at least 3 consecutive days with heat index of the day HImax (computed from Tmax) and of the night HImin (computed from Tmin) exceeding the local 90th percentile computed on all days of the control period (19812010). RH is assumed to be constant during the day and is computed, in GSOD data, from daily mean dewpoint and daily mean temperature. ${ }^{2}$ This assumption is

\footnotetext{
${ }^{1}$ http://www.wrh.noaa.gov/psr/general/safety/heat/heatindex.png.

${ }^{2} \mathrm{RH}=(e / \mathrm{es}) 100$, where $e$ is the observed water vapor pressure computed from daily mean dewpoint and es is the saturation water vapor pressure computed from daily mean temperature, using the Clausius-Clapeyron equation $\left\{\mathrm{es}=6.10 \exp \left[17.27 T(T+237.7)^{-1}\right]\right\}$.
}

acceptable in boreal spring (i.e., April through June) because of the very low variability in $\mathrm{RH}$ during the day. This assumption could, however, introduce a small bias in HI computation in summer, during the monsoon rainy season, in relationship with the diurnal cycle of precipitation. Unlike in GSOD, Tmax, and Tmin are not directly available in ERA-I and are computed from 6-hourly data. In particular, Tmax corresponds to the maximum value obtained between 1200 and 1800 UTC, which does not exactly correspond to the observed Tmax, which occurs between 1300 and 1700 UTC. The 6-hourly resolution of ERA-I therefore introduces the first bias in the study.

\section{c. Assessing confidence in ERA-I}

ERA-I is chosen for this study because it offers a better representation of HImin and HImax climatology and variability in the western Sahel in comparison with the Modern-Era Retrospective Analysis for Research and Applications (MERRA) (Rienecker et al. 2011). Indeed, ERA-I captures well the observed annual cycle of HImin and HImax (not shown) over the studied region, with two thermal peaks in boreal spring and autumn, the former being warmer than the latter. However, HImax is underestimated at about $7 \%$ and HImin is overestimated at about $5 \%$. Interannual variability over 1979-2014 of spatially averaged anomalies of HImax and HImin in boreal spring is correctly represented with a correlation between GSOD and ERA-I of 0.76 and $0.88,{ }^{3}$ respectively (Fig. 2). The good agreement with synoptic observations regarding

\footnotetext{
${ }^{3}$ Correlations reported in the paper are all statistically significant at $p=0.05$ according to the Bravais-Pearson test.
} 

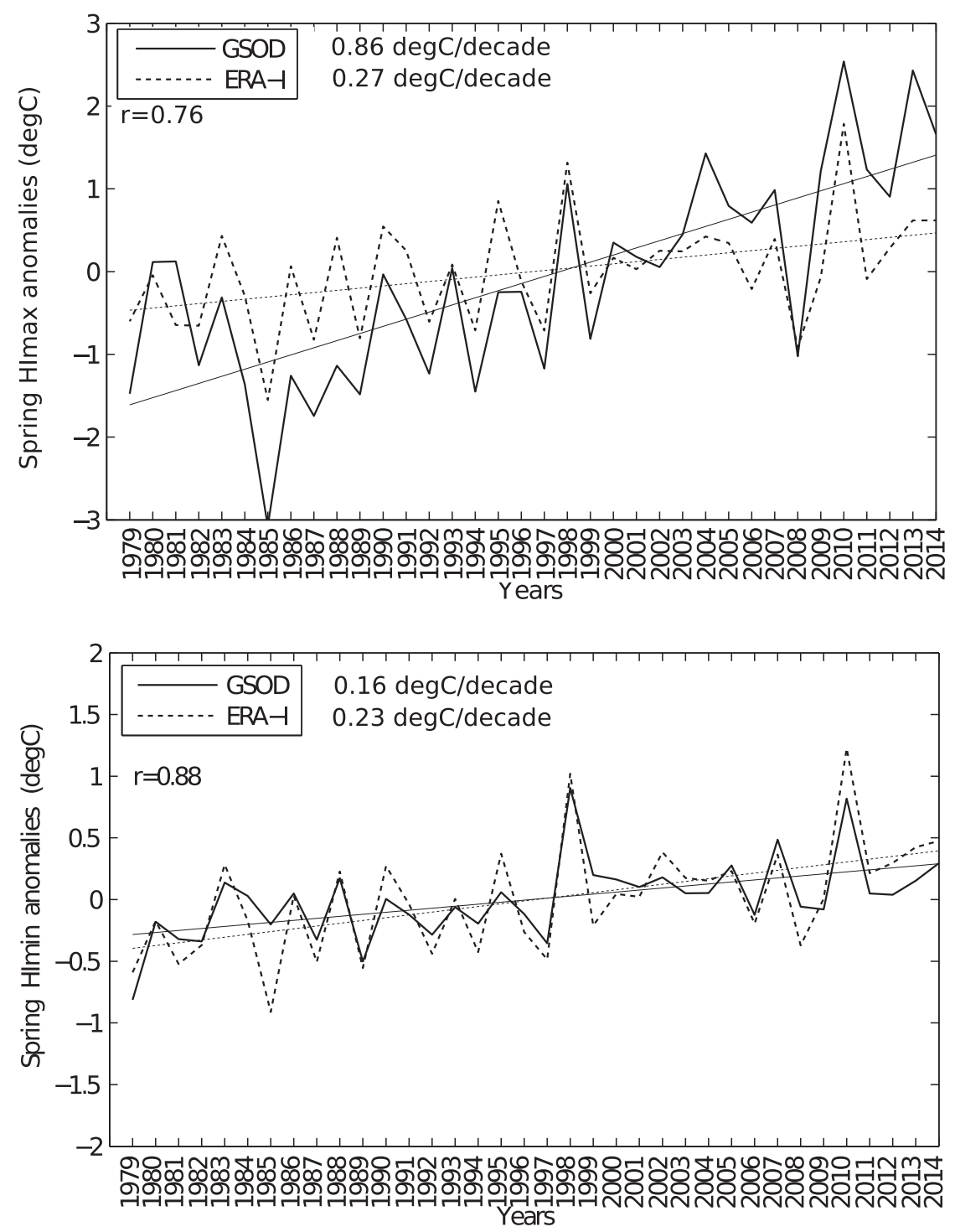

FIG. 2. Interannual variations of (top) HImax and (bottom) HImin anomalies (computed as difference from 1979-2014 climatology) over the western Sahel in boreal spring (April-June) for GSOD (mean over the 48 available stations) and ERA-I (mean over grid points belonging to domain of study). The linear slopes (in ${ }^{\circ} \mathrm{C}$ decade $^{-1}$ ) and correlations $r$ between ERA-I and GSOD are significant at $p=0.05$ according to, respectively, Student's $t$ test and the Bravais-Pearson test.

HImin and HImax climatology and variability is obtained on average over the domain of study (the rectangular area in Fig. 1). However, when averaging over the closest grid points to the synoptic stations, both ERA-I and MERRA show considerably lower skill. This indicates that reanalysis offers a good representation of large-scale features but totally misses the local gridpoint scale. Both datasets show significant warming over the studied period with a larger amplitude for HImax than for HImin. The spatially averaged linear trends in GSOD equal, respectively, $0.86^{\circ}$ and $0.16^{\circ} \mathrm{C}$ decade ${ }^{-1}$. ERA-I reproduces well HImin annual variations but underestimates HImax trend and variability. HImax shows positive anomalies from the 1990s with four defined peaks occurring in 1998, 2004, 2010, and 2013, with 2010 being the warmest year in the western Sahel (Fig. 2). HImin also shows positive anomalies from the 1990s with two maxima in 1998 and 2010, which are perfectly captured by ERA-I.

\section{HW characteristics}

\section{a. Interannual variations of $H W$ characteristics}

In this section, HW characteristics are analyzed in GSOD and ERA-I. It is important to note that the 
comparison between gridded and nongridded datasets presents some uncertainties, particularly because of the lower density of stations. To reduce these uncertainties, we tested two approaches. The first computes HW characteristics on the closest grid points to the synoptic stations. The second computes HW metrics for each station in GSOD and each grid point in ERA-I over the domain of study presented in Fig. 1 (which is homogeneously covered by GSOD stations). HW metrics are then averaged over the 48 available stations in GSOD and over grid points in ERA-I. A better agreement is obtained with the second approach. Four metrics are analyzed:

1) HW extent (\%): the percentage of stations (GSOD) or grid points (ERA-I) facing an HW computed as the ratio of stations (grid points) within a specific HW event to the total number of stations (grid points)

2) HW frequency (days): the number of HW days per spring

3) HW duration (days): the mean length of HW events per spring

4) HW intensity $\left({ }^{\circ} \mathrm{C}\right)$ : the average daily HImax during HW events per spring

HW spatial extent is presented in Fig. 3 and shows that HWs occur predominantly in boreal spring (April through June), when thermal conditions are already critical for human health. HWs are localized with spatial extent varying, in GSOD, between $2 \%$ (i.e., only 1 station in $\mathrm{HW}$ ) and $35 \%$ (i.e., 17 stations) of the total number of stations. HWs tend to cover larger areas since the mid-1990s with three important events covering more than $20 \%$ of the domain (at least 10 stations) occurring in 1998, 2010, and 2013, with 2010 showing the largest extent (35\%) over the 1979-2014 period. ERA-I captures the increase in spatial extent of HWs since the mid-1990s and reproduces the most severe events (1998 and 2010) but tends to overestimate the area covered by HWs.

We focus now on the warmest season of the western Sahel identified in Fig. 3 (viz., the April-June season) and investigate the temporal evolution of HW characteristics over 1979-2014. HW frequency shows a significant increase over the studied period with a linear trend equal to 1.21 days decade $^{-1}$ in GSOD (Fig. 4a). The years 2010 and 2013 show the largest mean number of HW days (11 days) over the whole period. Other important events occurred in 1998, 2003, and 2006. ERA-I reproduces well the positive trend of HW frequency and its interannual variability (correlation between GSOD and ERA-I equal to 0.6) but overestimates the number of HW days. Mean
HW duration shows a positive trend equal to 0.46 days decade $^{-1}$ with three important events lasting, on average, more than 6 days: 2003, 2006, and 2014 (Fig. 4b). In some particular stations, maximum HW duration reached 15 days, 13 days, and 14 days in 2003,2006 , and 2014, respectively. It is interesting to note that 2010 was an exceptional year in terms of spatial extent and HW frequency but not in terms of mean duration (equal on average to 5 days), with the exception of two stations in Burkina Faso and Niger where HW duration reached 9 and 10 days, respectively. ERA-I captures reasonably well the HW duration variability (correlation between GSOD and ERA-I equal to 0.4). However, the duration of the longest HWs is underestimated and that of the shortest is overestimated (Fig. 4b). HW mean intensity in GSOD shows a significant increase of $0.6^{\circ} \mathrm{Cdecade}^{-1}$ over the $1974-2014$ period (Fig. 4c). In the majority of $\mathrm{HW}$ events, mean intensity exceeds $52^{\circ} \mathrm{C}$, which is a dangerous threshold on human health (Steadman 1979). Important peaks are found in 1993, 2006, 2010, and 2013 with mean intensity larger than $54^{\circ} \mathrm{C}$, which is an extremely dangerous threshold on human health (Steadman 1979). ERA-I underestimates HW intensity and misrepresents its positive trend over 1979-2014 as well as its interannual variability.

\section{b. Relationships between HW characteristics}

Relationships between HW characteristics are investigated by representing the HW frequency (Figs. 5a,b) and intensity (Figs. 5c,d) as a function of mean extent and duration. Figures $5 a, b$ compute a probability of occurrence per year of each category of HWs depending on the mean extent and duration. HWs are classified into three main categories depending on their frequency (very frequent, frequent, or rare) and mean intensity (determined from HImax). Following the threshold levels of HI published by Steadman (1979) and by the U.S. National Weather Service, HImax is compared to $54^{\circ} \mathrm{C}$. Values varying between $40^{\circ}$ and $54^{\circ} \mathrm{C}$ are considered dangerous for human health, and those exceeding $54^{\circ} \mathrm{C}$ are considered extremely dangerous. The three HW categories are presented in Table 1 . The first group is the most frequent (more than $20 \mathrm{HW}$ days $\mathrm{yr}^{-1}$; i.e., $720 \mathrm{HW}$ days over 1979-2014) and corresponds to HWs with dangerous mean intensities varying between $51^{\circ}$ and $54^{\circ} \mathrm{C}$ (Fig. 5a). These HW events are short (3-5 days) and localized ( $2 \%-$ $8 \%$ corresponding to $1-4$ stations). The second group has a medium frequency ( 0.5 to 2 days $\mathrm{yr}^{-1}$; i.e., 18 to 72 HW days over 1979-2014) and corresponds to HWs with extremely dangerous mean intensities of $54^{\circ}$ to $56^{\circ} \mathrm{C}$. 

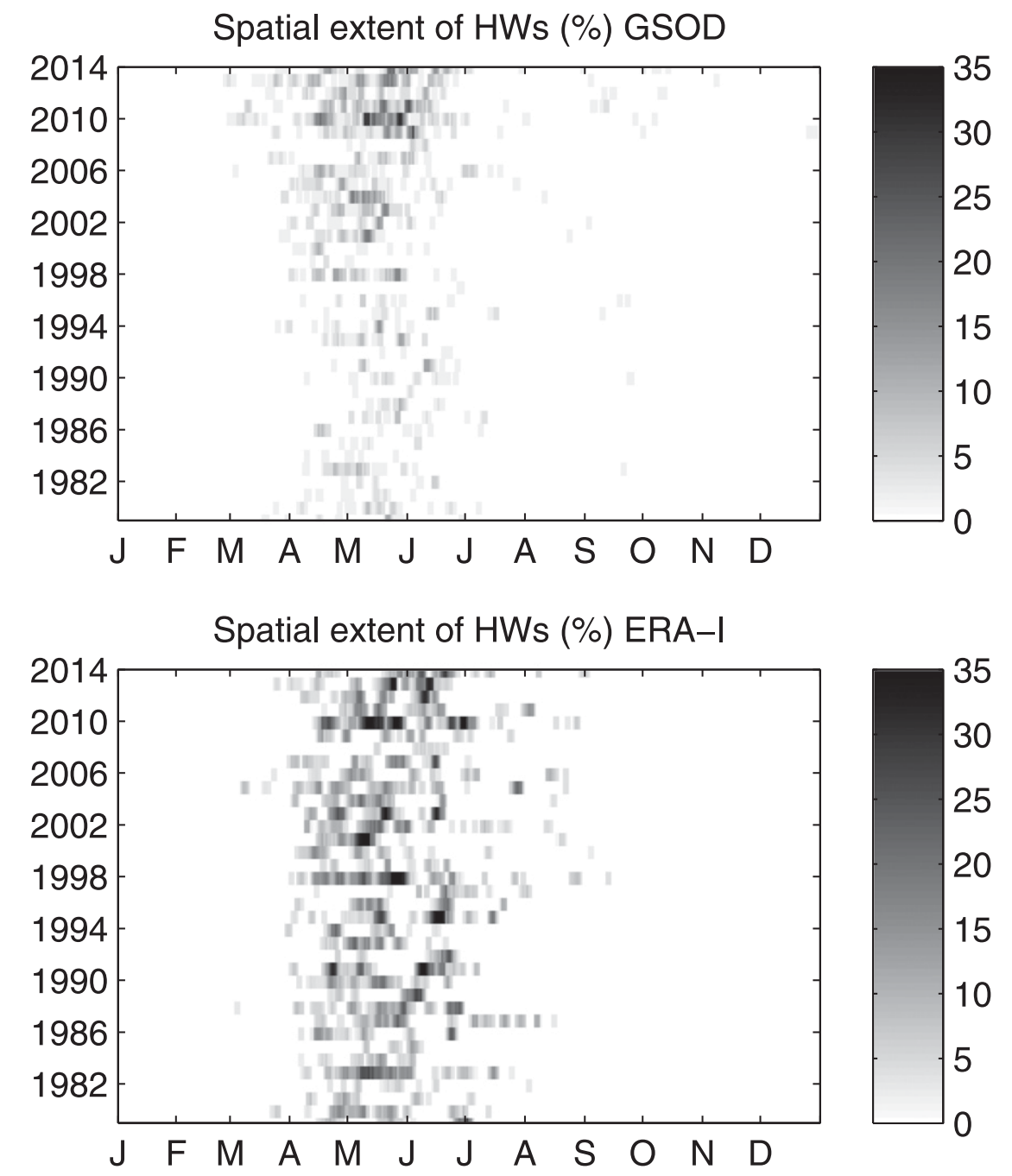

FIG. 3. Percentage of (top) stations in GSOD and (bottom) grid points in ERA-I facing an HW computed as the ratio of stations (grid points) within a specific HW event to the total number of stations (grid points).

These HWs have a spatial extent of $8 \%$ to $20 \%$ (4 to 10 stations) and mean duration of 3 to 9 days. The third group is rare (less than 0.5 days $\mathrm{yr}^{-1}$; i.e., 18 days over 1979-2014) but have extremely high intensities (larger than $\left.56^{\circ} \mathrm{C}\right)$. It corresponds to long (9-15 days) and weekly extended $(2 \%-4 \%)$ HWs. The last two groups are the most dangerous for human health and are becoming more frequent since 1998 (not shown). ERA-I captures well the three main categories of HWs described above (Fig. 5b) but tends to overestimate their mean frequency and underestimate their mean intensity (Fig. 5d).

It is evident that ERA-I have difficulties in representing HW characteristics, interannual variability, and trend. Its credibility in assessing the physical mechanisms associated with climatic trends and variability can be criticized, as already pointed out in some existing studies (Kalnay et al. 1996; Schär and Jendritzky 2004; Bengtsson et al. 2004). The sources of uncertainties come from deficiencies in the observing system, the data assimilation, and the realism of the assimilating model. We thus have to be aware about these limitations when using the reanalysis. However, these datasets remain useful to investigate the key mechanisms associated with warm extremes because they offer a complete synthesis of the energy budget components and feedbacks that control temperature anomalies, including atmospheric dynamics and radiative and surface fluxes. In particular, in this study, we will examine the processes that modulate 

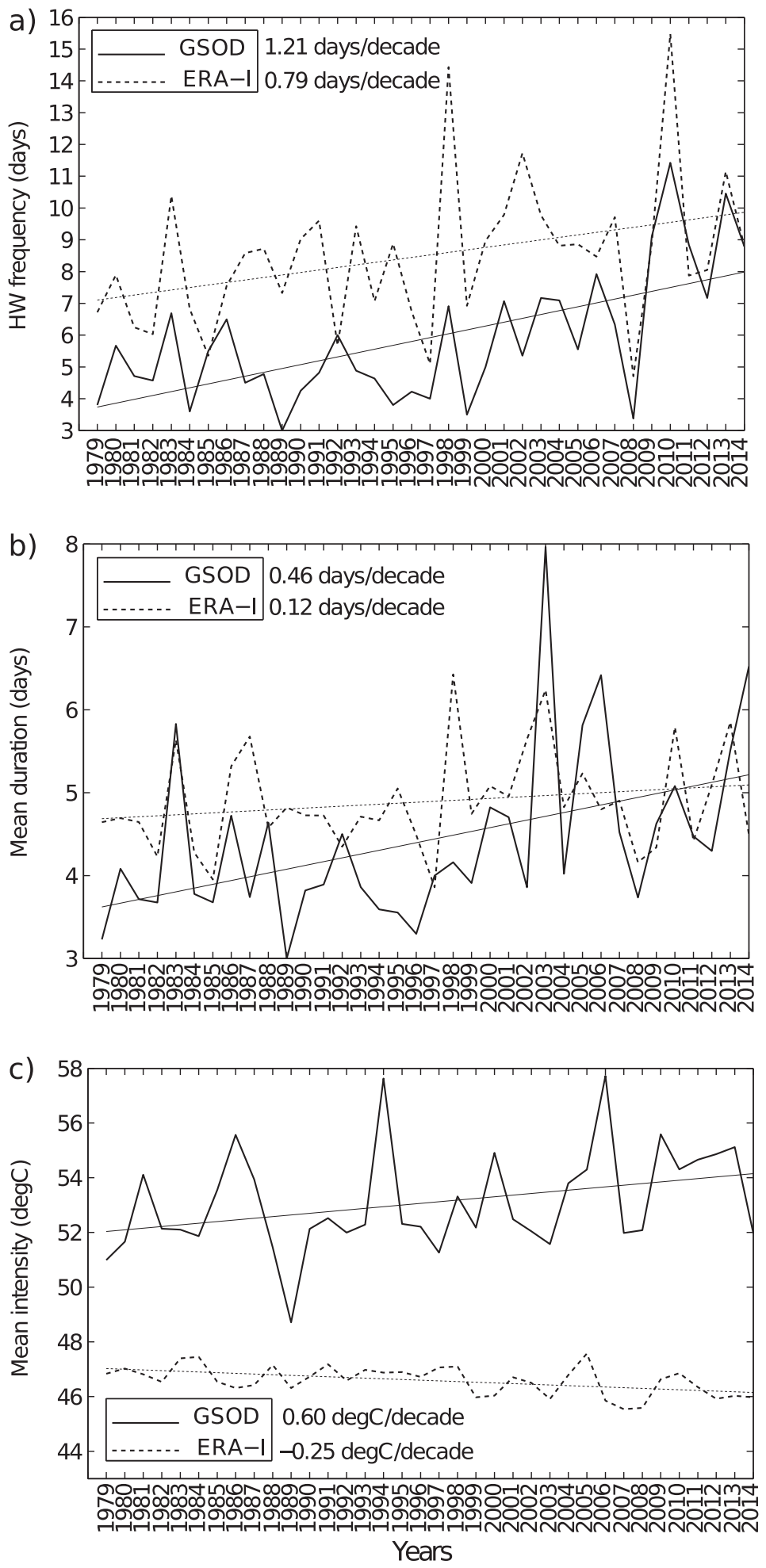

FIG. 4. Temporal evolution over 1979-2014 of (a) HW frequency, (b) HW mean duration, and (c) HW mean intensity computed from HImax for GSOD and ERA-I in boreal spring. HW characteristics are calculated for each station or grid point and then averaged over the studied domain (mean over the 48 available stations in GSOD and over grid points in ERA-I). The linear slopes (in ${ }^{\circ} \mathrm{C}$ decade ${ }^{-1}$ ) are significant at $p=0.05$ according to Student's $t$ test. 
a) HW frequency (days/year) GSOD

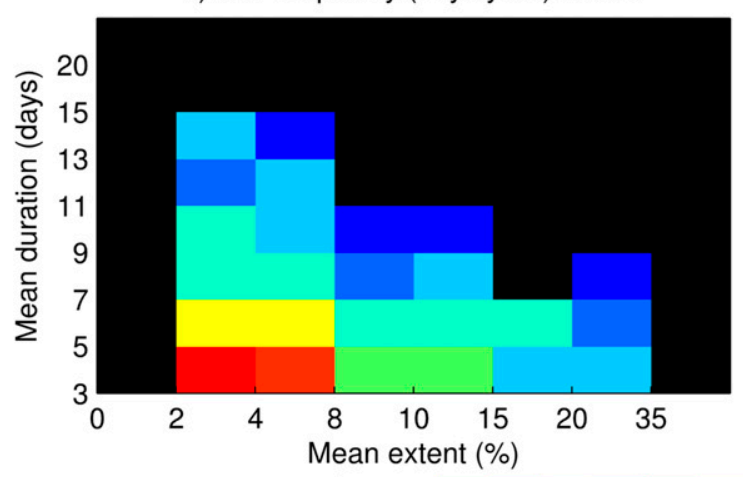

b) HW frequency (days/year) ERA-I

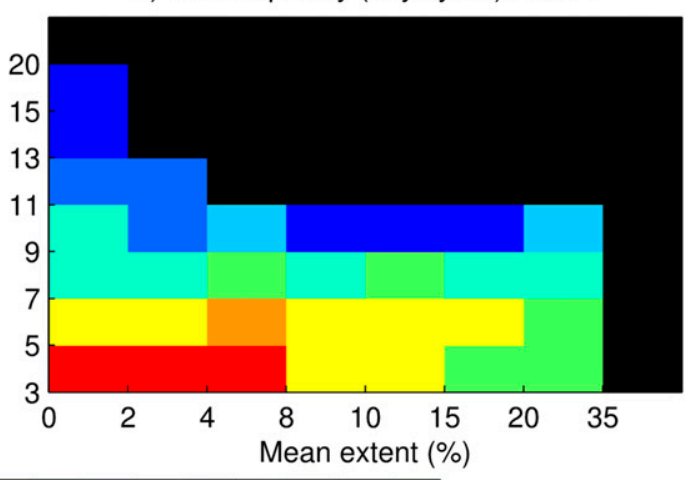

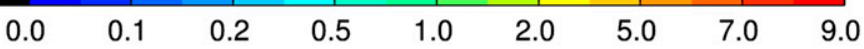

c) Mean intensity (degC) GSOD

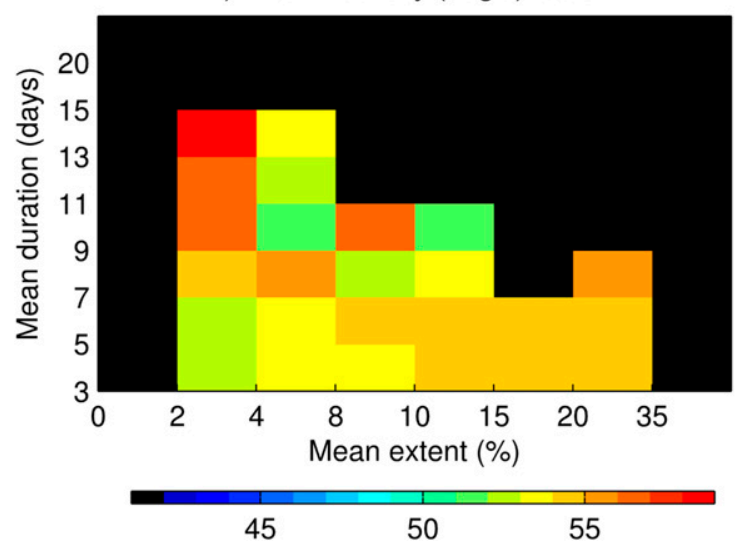

d) Mean intensity (degC) ERA-I

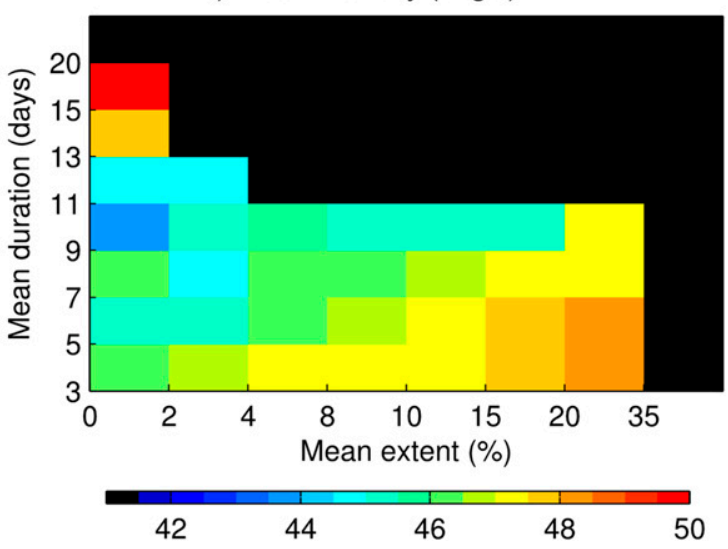

FIG. 5. HW frequency as a function of mean extent and duration for (a) GSOD and (b) ERA-I in boreal spring. For each bin, the number of HW days is averaged over 1979-2014. HW mean intensity as a function of mean extent and duration for (c) GSOD and (d) ERA-I in boreal spring (April-June). For each bin, mean intensity is computed as mean HImax during HW periods averaged over 1979-2014.

HW frequency, which is well represented in ERA-I (correlation with GSOD equal to 0.6), focusing on a spring 2010 case study and interannual variability.

\section{Mechanisms associated with spring $2010 \mathrm{HW}$}

\section{a. Surface energy budget analysis}

To investigate the mechanisms responsible for HWs in the Sahel, the surface energy budget is analyzed using ERA-I fields (see section 2a). The energy budget is useful to assess the sources and sinks of surface energy during an HW event and identify the physical processes responsible of the temperature distribution and the growth and decay of warm anomalies (Zhang et al. 2011). The variation in time of surface temperature $T$ is expressed as follows:

$$
C_{s} \frac{\partial T}{\partial t}=\Delta \mathrm{SWR}+\Delta \mathrm{LWR}+\Delta \mathrm{SH}+\Delta \mathrm{LH}
$$

TABLE 1. Classification of HWs in the Sahel according to their mean frequency and intensity in GSOD data.

\begin{tabular}{|c|c|c|c|c|}
\hline & HW frequency & Mean intensity & Mean duration & Mean spatial extent \\
\hline First HW category & $\begin{array}{l}\text { Very frequent: }>20 \text { days } \mathrm{yr}^{-1} \\
\text { (i.e., }>720 \mathrm{HW} \text { days in } 36 \text { years) }\end{array}$ & $\begin{array}{l}51 \leq \text { HImax }<54^{\circ} \mathrm{C} \\
\text { dangerous }\end{array}$ & $3-5$ days & $2 \%-8 \%$ (1-4 stations) \\
\hline Second HW category & $\begin{array}{l}\text { Frequent: } 0.5-2 \text { days yr }{ }^{-1} \\
\quad \text { (i.e., } 18-72 \mathrm{HW} \text { days in } 36 \text { years) }\end{array}$ & $\begin{array}{l}54 \leq \mathrm{HImax}<56^{\circ} \mathrm{C} \\
\text { extremely dangerous }\end{array}$ & 3-9 days & $8 \%-20 \%$ (4-10 stations) \\
\hline Third HW category & $\begin{array}{l}\text { Rare: }<0.5 \text { days yr }{ }^{-1} \\
\quad \text { (i.e., }<18 \mathrm{HW} \text { days in } 36 \text { years) }\end{array}$ & $\begin{array}{l}\mathrm{HImax} \geq 56^{\circ} \mathrm{C} \\
\quad \text { extremely dangerous }\end{array}$ & 9-15 days & $2 \%-4 \%$ (1-2 stations) \\
\hline
\end{tabular}


TABLE 2. List of variables used in the study.

\begin{tabular}{ll}
\hline \hline \multicolumn{1}{c}{ Variable } & \multicolumn{1}{c}{ Variable name in ERA-I } \\
\hline Surface net SWR & Surface net solar radiation \\
Surface net LWR & Surface net thermal radiation \\
Clear-sky surface net shortwave radiation (clear-sky SWR) & Surface net solar radiation, clear sky \\
Clear-sky surface net thermal radiation (clear-sky LWR) & Surface net thermal radiation, clear sky \\
Surface latent heat flux (LH) & Surface latent heat flux \\
Surface sensible heat flux (SH) & Surface sensible heat flux \\
Surface GHE & Surface thermal radiation downward \\
Total column precipitable water & Total column water vapor \\
Vertically integrated moisture flux convergence & Vertical integral of divergence of moisture flux
\end{tabular}

where $C_{s}$ is the surface layer heat capacity, SWR is the surface net shortwave radiation, LWR is the surface net longwave radiation, $\mathrm{SH}$ is the surface sensible heat flux, and $\mathrm{LH}$ is the surface latent heat flux. All fluxes are counted positive toward the surface (i.e., a gain for the surface). Variables and acronyms used in this section are summarized in Table 2.

The surface energy budget is analyzed for HWs occurring during spring 2010 [April-June 2010 (AMJ10)], which is an unprecedented season in terms of HW frequency in the Sahel (Fig. 4a). Figure 6 displays HImax and HImin anomalies during spring 2010 and shows the strong warming observed during this particular season over the western Sahel and Sahara, as well as along the
Guinean coasts. The observed warming was amplified by RH in AMJ10 (not shown). The additional warming due to RH was evaluated by computing HImax and HImin anomalies after neutralizing the effect of $\mathrm{RH}$ [i.e., $\mathrm{RH}=0$ in Eq. (1)]. The warming effect of $\mathrm{RH}$ is evident and clearly confirms the necessity to consider RH in the definition of HWs to determine the human-perceived temperature.

ERA-I captures well the HImax and HImin anomalies at the large scale (Fig. 6). This is particularly true over the selected domain of this study (region enclosed within the dashed box in Fig. 6). ERA-I can thus be used to assess the large-scale physical mechanisms associated with the extreme 2010 event. However, the local-scale

a) AMJ10 HImax anomalies

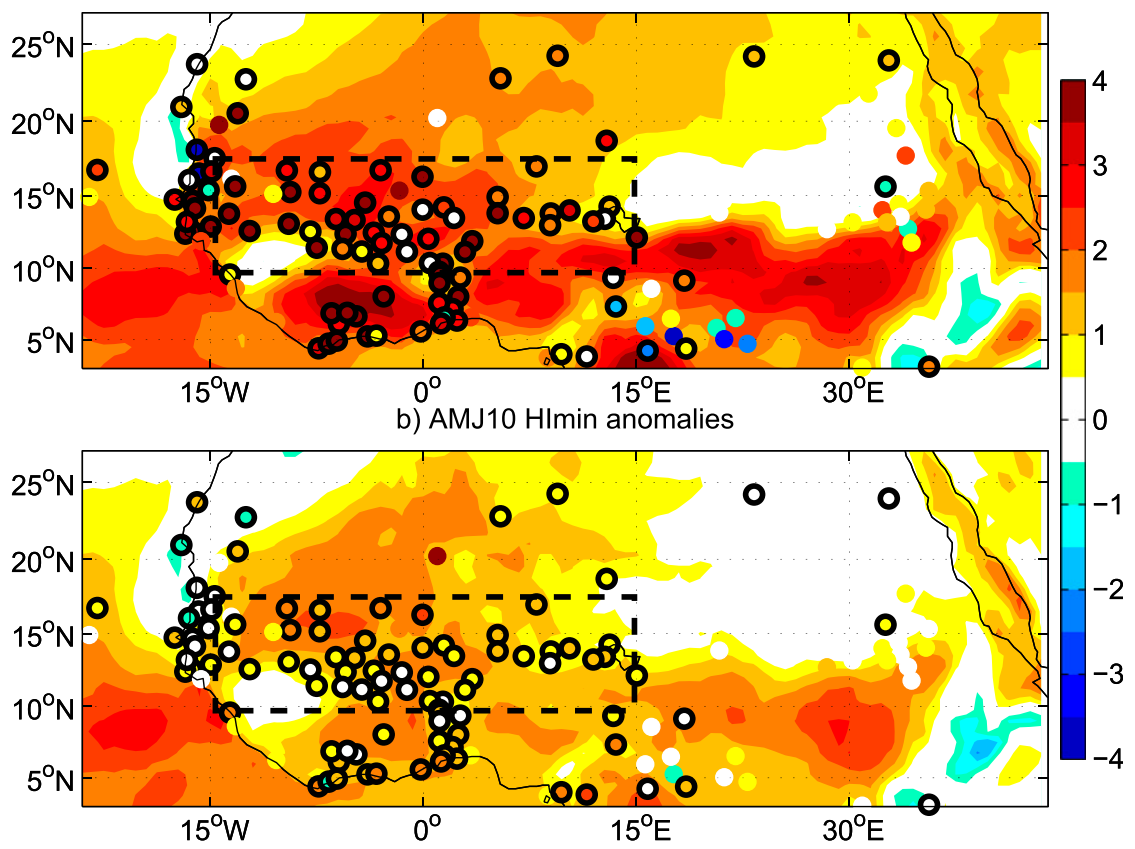

FIG. 6. AMJ10 (a) HImax anomalies and (b) HImin anomalies for ERA-I (shading) and GSOD (circles) data. Anomalies are computed as the difference between HImax and HImin during spring 2010 and 1979-2014 climatology. Stations having at least 50\% of available daily entries are marked by a black circle. White areas are not significant at $p=0.05$ according to Student's $t$ test. 
a) AMJ10 Surface Net SWR anomalies (W m-2) ERA-I

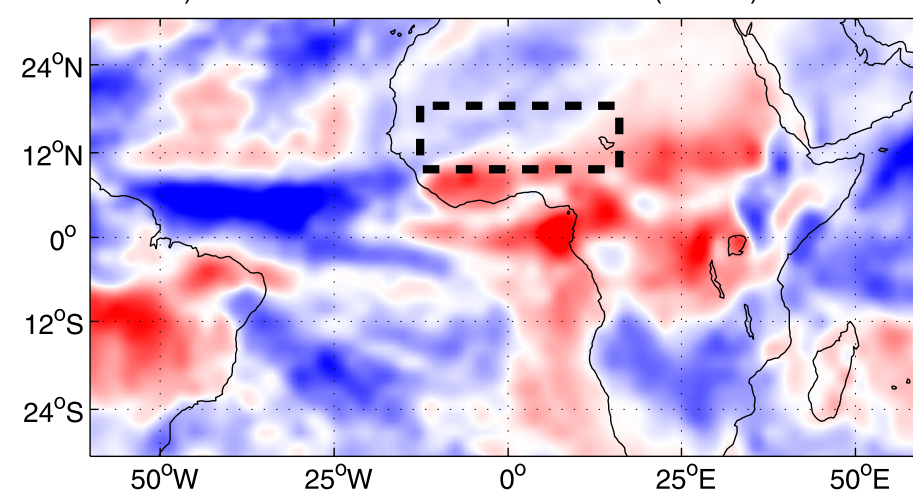

b) AMJ10 Surface Net LWR anomalies (W m-2) ERA-I

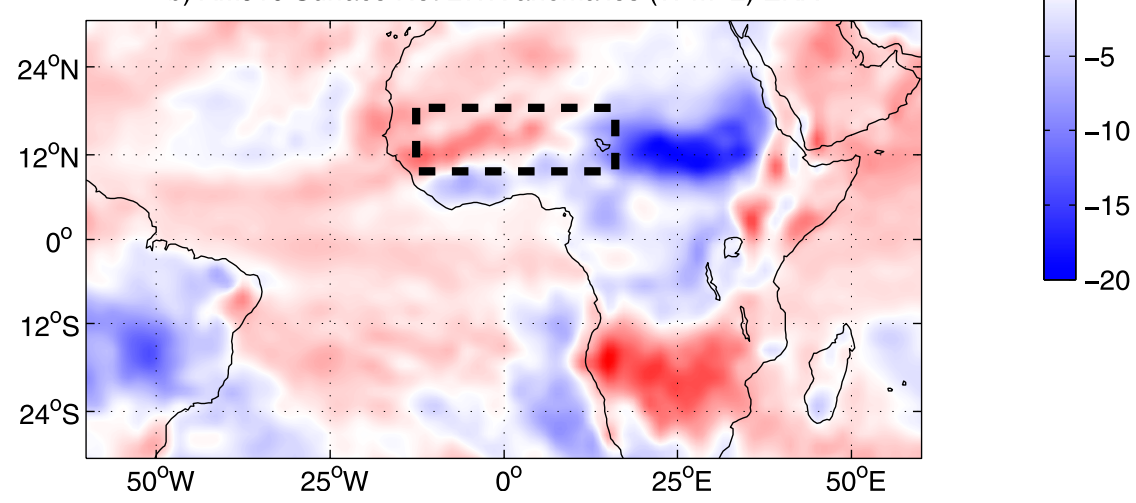

FIG. 7. AMJ10 (a) surface net SWR anomalies and (b) surface net LWR anomalies in ERA-I. Anomalies are computed as the difference between surface fluxes during spring 2010 HW days and 1979-2014 climatology. Radiative fluxes are counted positive downward. Positive anomalies for both SWR and LWR represent a gain of radiative energy by the surface. White areas are not significant at $p=0.05$ according to Student's $t$ test.

features are misrepresented and confirm the necessity to focus on the regional scale in ERA-I to guarantee a better agreement with synoptic observations. To investigate the factors responsible for warm anomalies during spring 2010, the surface energy budget components are computed for HW days in ERA-I to identify the sources and sinks of energy during this warm event.

\section{b. Surface radiative fluxes}

In this section, we investigate the role of surface radiative fluxes in temperature heating during spring 2010, focusing on the surface net shortwave (SWR) and longwave (LWR) radiative flux anomalies for HW days during AMJ10 (Fig. 7). The SWR response is shown in Fig. 7a. Positive anomalies of surface net SWR are found in the southern part of the studied domain and along the Guinean coasts, implying that more SWR is absorbed during spring 2010, contributing to heating the surface and to increasing warm temperature anomalies. Strong positive anomalies of surface LWR are observed in most of the studied domain, indicating that more infrared radiation is radiated back to Earth's surface (Fig. 7b).
Downward LWR contributed significantly to temperature warming in the western Sahel (Fig. 6b) and to the increased occurrence of HWs in spring 2010. To assess the quality of ERA-I in representing surface radiative fluxes, a comparison with the Clouds and the Earth's Radiant Energy System Synoptic (CERES-SYN1deg) product (Rutan et al. 2015) is carried out (see appendix). We clearly show that the surface net SWR and LWR patterns obtained in ERA-I are in qualitative agreement with the CERES-SYN1deg product. We can therefore trust this reanalysis to document and understand the physical processes associated with HWs in the Sahel.

\section{1) SURFACE CRE}

Section $4 \mathrm{~b}$ highlights the significant contribution of LWR to temperature warming over the studied domain in AMJ10 and that of SWR in the southern part. Radiative fluxes are particularly affected by clouds and water vapor. It is therefore important to document their role in AMJ10 radiative warming. Clouds contribute to cooling (heating) the surface by reflecting shortwave radiation (absorbing and emitting infrared radiation known as the 
a) AMJ10 Surface SW CRE anomalies (W m-2) ERA-I
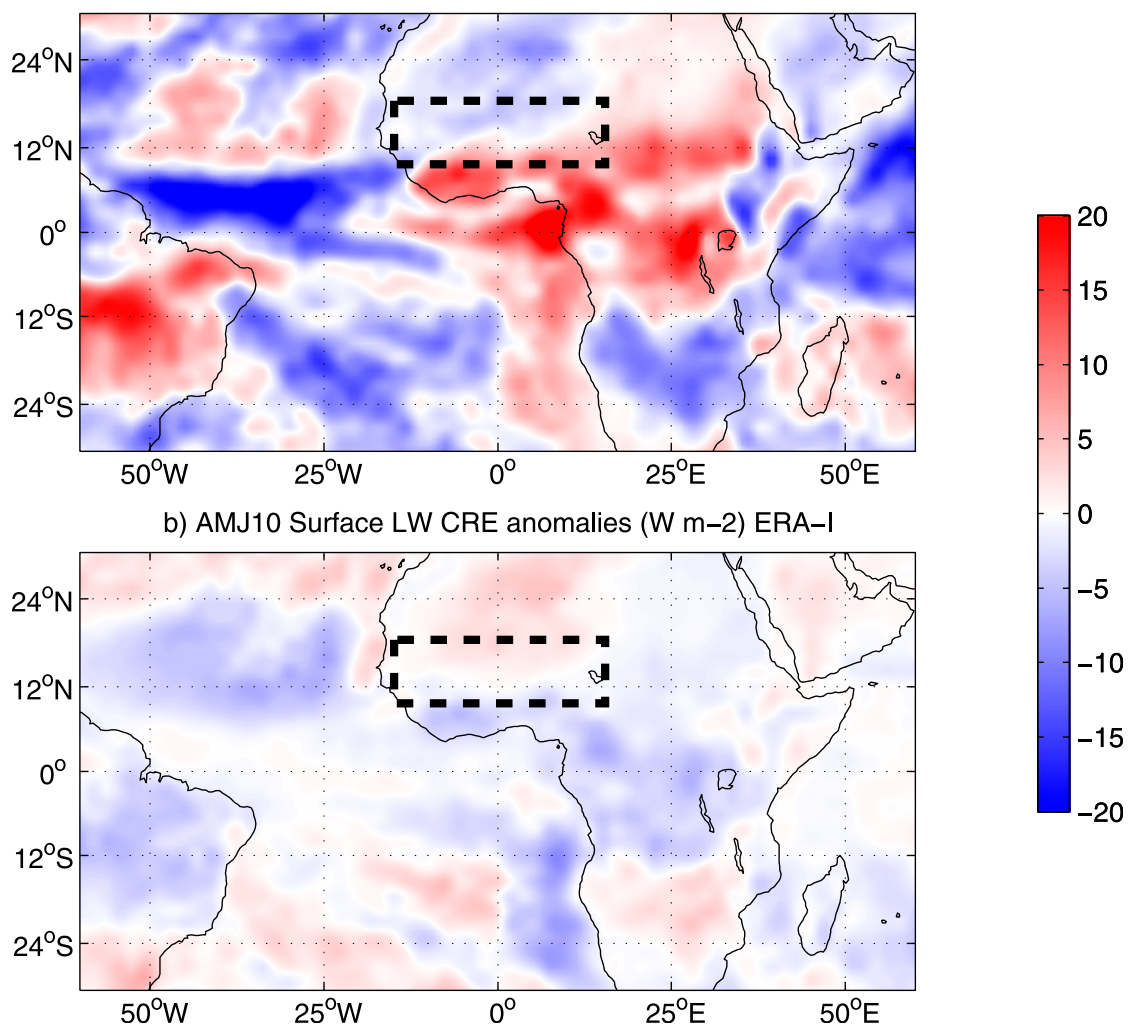

FIG. 8. AMJ10 (a) surface net shortwave (SW) CRE anomalies and (b) surface net longwave (LW) CRE anomalies. Cloud radiative effect is computed as the difference between allsky and clear-sky surface net SWR and LWR. Anomalies are computed as the difference between CRE during spring 2010 HW days and 1979-2014 climatology. Positive anomalies for both SW CRE and LW CRE represent a gain of radiative energy by the surface. White areas are not significant at $p=0.05$ according to Student's $t$ test.

cloud greenhouse effect). Cloud radiative effect (CRE) is computed as the difference between all-sky and clear-sky surface net SWR and LWR (Bony et al. 2004). (Surface net SW and LW CRE anomalies of ERA-I and CERES-SYN1deg are displayed in Fig. 8 and appendix Fig. A1.) The pattern of SW CRE anomalies is very similar to SWR anomalies (cf. Fig. 7a and Fig. 8a), emphasizing the important role played by clouds in regulating the incoming shortwave radiation. The heating observed in the southern part of the studied domain and along the Guinean coasts is explained by the increased downward SWR associated with a reduction in cloud cooling effect that results from the reduction in the total cloud cover (not shown). The surface longwave and shortwave effects of clouds are of opposite sign (cf. Fig. 8a and Fig. 8b); the increased total cloud cover in the western Sahel is associated with increased downward LWR and cloud warming. However, the longwave effects are smaller so that the net radiative effect of clouds is dominated by the shortwave effects. Bouniol et al. (2012) analyzed the radiative effects of clouds over the Sahel in spring season. They emphasize the major role of cirrus and anvil clouds in reducing incoming SWR and the important impact of midlevel clouds in increasing downward LWR. Longwave cloud radiative effects explain the spatial pattern of the net LWR but contribute only little to the LWR intensity over land (cf. Fig. $7 \mathrm{~b}$ and Fig. $8 b$ ). In addition, the strong longwave heating observed in the western part of the studied domain is not explained by surface LW CRE anomalies. Other physical processes are involved to explain downward longwave radiative anomalies in spring 2010.

\section{2) ROLE OF WATER VAPOR FEEDBACK}

In spring 2010, anomalous LW heating contributed largely to increasing warm temperature anomalies in the western Sahel (Fig. 7b). LWR is affected by both clouds and water vapor. In section $4 \mathrm{~b}(1)$, we showed that clouds have a small impact on LWR anomalies (Fig. 8b). Indeed, the major contributor to the anomalous downward LWR is water vapor, as highlighted in previous studies (e.g., Guichard et al. 2009). This is emphasized by the 
a) AMJ10 total column precipitable water anomalies $(\mathrm{Kg} \mathrm{m}-2)$

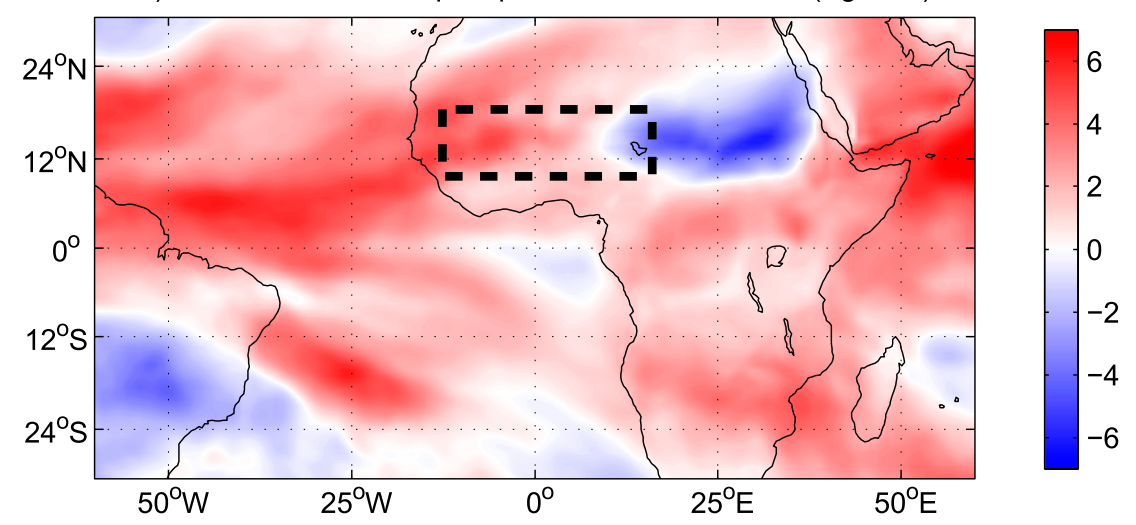

b) AMJ10 GHE anomalies (W m-2)

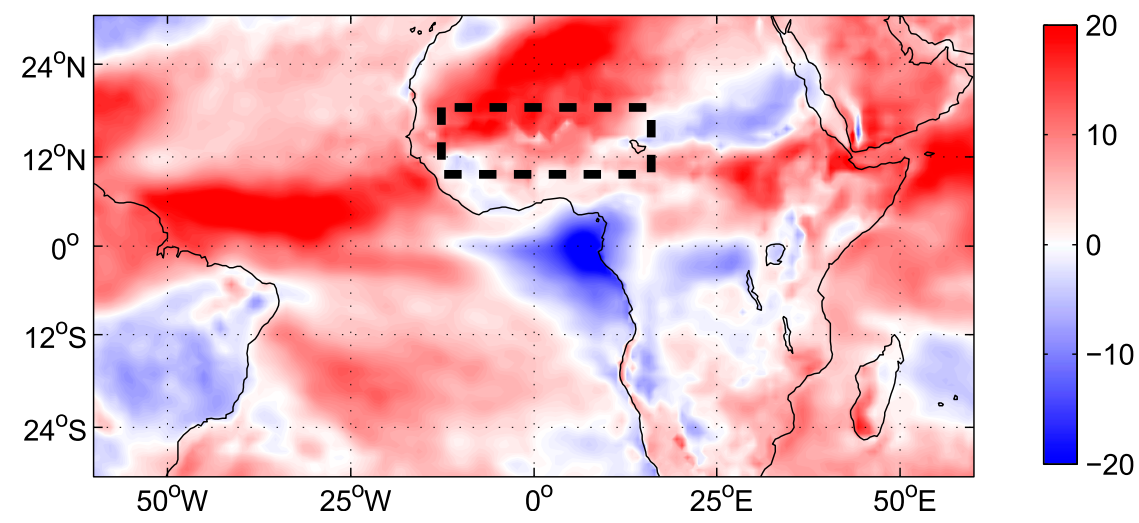

FIG. 9. AMJ10 (a) total column precipitable water and (b) surface GHE anomalies. The GHE is defined as the downward LWR at the surface. Positive anomalies of GHE represent a gain of LW radiative energy by the surface. White areas are not significant at $p=0.05$ according to Student's $t$ test.

close spatial agreement between the surface net LWR (Fig. 7b) and the total column precipitable water anomalies (Fig. 9a) over the Sahelian band. Water vapor anomalies were particularly strong in spring 2010 in the western Sahel and over the tropical Atlantic Ocean, enhancing the greenhouse effect (GHE) and contributing to temperature extreme warming. The GHE is defined in this study as the downward LWR at the surface. It is measured for all-sky situations and accounts for surface heating by both natural (water vapor and clouds) and anthropogenic GHE. GHE was anomalously high in spring 2010 almost everywhere over the tropical Atlantic Ocean and the African continent (Fig. 9b), playing an important role in surface temperature warming. The enhanced GHE anomalies are mainly explained by the abundant water vapor within the atmosphere, as it is apparent from the similarity between the two patterns (Figs. 9a,b). As temperature is increasing over the tropical Atlantic Ocean and Guinean coasts, water holding capacity of the air is increasing, further enhancing precipitable water amount within the atmosphere by favored surface evaporation, resulting in an elevated water vapor GHE over this region (Fig. 9b). We can also identify the small contribution from clouds, particularly over the $\left[13^{\circ}-30^{\circ} \mathrm{N} ; 10^{\circ} \mathrm{W}-10^{\circ} \mathrm{E}\right]$ domain (cf. Figs. $8 \mathrm{~b}$ and $9 \mathrm{~b}$ ), further enhancing the GHE over the western Sahel and the neighboring regions.

\section{c. Moisture flux convergence}

As highlighted in section $4 \mathrm{~b}(2)$, changes in atmospheric water vapor content are the principal source for the anomalous LWR. It is therefore important to investigate the origin of the abundant water vapor within the atmosphere in AMJ 2010 by analyzing the horizontal moisture transport. For that purpose, we examine here the vertically integrated moisture flux convergence, given by $-\int_{0}^{p_{s}} \nabla \cdot(q \mathbf{v})(d p / g)$ (where $q$ is specific humidity, $\mathbf{v}$ is the horizontal wind, $p$ is the pressure, and $g$ is the acceleration of gravity). Moisture flux convergence anomalies during AMJ 2010 are shown in Fig. 10. 


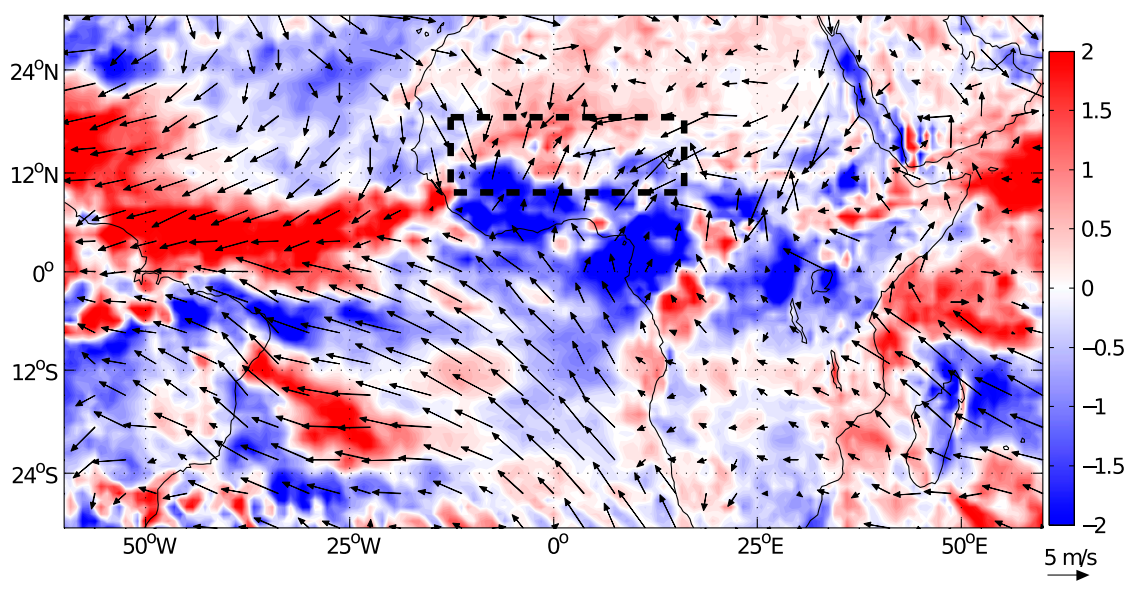

FIG. 10. AMJ10 vertically integrated moisture flux convergence anomalies and AMJ10 winds at the 925-hPa pressure level. Positive (negative) values correspond to areas of anomalous moisture flux convergence (divergence). Anomalies are computed as the difference between fluxes during spring $2010 \mathrm{HW}$ days and 1979-2014 climatology. White areas are not significant at $p=0.05$ according to Student's $t$ test.

Convergence anomalies are found in the northern part of the studied domain (for latitudes north of $12^{\circ} \mathrm{N}$ ). Anomalous flux divergence is diagnosed in northern tropical Atlantic and close to the Guinean coasts, suggesting that these two oceanic regions were the major sources of moisture during AMJ 2010. Moisture produced by surface evaporation over the northern tropical Atlantic and the Guinean coasts is advected into the continent by low-level horizontal winds (Fig. 10), increasing water vapor anomalies in the Sahel. The atmospheric circulation played an important role in increasing warm temperature anomalies by advecting moisture into the Sahel and sustaining the water vapor GHE.

\section{d. Turbulent surface fluxes}

In addition to radiative fluxes, surface turbulent fluxes anomalies can modify the surface heating during spring 2010. Anomalies of sensible and latent heat flux are shown in Fig. 11. The anomalies are small in the western Sahel (smaller than $|5| \mathrm{W} \mathrm{m}^{-2}$ ) and contribute weakly to temperature anomalies. The surface sensible heat flux anomalies result from surface wind speed anomalies and from the difference in temperature between the surface and the air at $10 \mathrm{~m}$. In spring 2010, SH flux was anomalously weak in the western Sahel associated with low air-surface temperature differences and did not contribute to the excessive atmospheric warming during that season. The surface latent heat flux anomalies result from surface wind speed anomalies and from the difference in specific humidity between the surface and the air at $10 \mathrm{~m}$. In spring 2010, LH flux was higher than the climatological values in the western Sahel associated with both larger air-surface humidity vertical gradient and stronger low-level winds. Anomalous LH release into the atmosphere exceeding $10 \mathrm{~W} \mathrm{~m}^{-2}$ is found in the northern tropical Atlantic (between $10^{\circ}$ and $50^{\circ} \mathrm{W}$ ) and close to the Guinean coasts associated with stronger low-level winds and warmer sea surface temperatures. These regions of higher evaporation anomalies correspond to those of anomalous moisture flux divergence shown in Fig. 10 and act as a major source of water vapor for the Sahelian atmosphere during spring 2010.

\section{Mechanisms associated with $\mathrm{HW}$ variability at interannual time scale}

\section{a. The prevailing contribution of radiative fluxes}

The surface energy budget presented in section $4 \mathrm{a}$ highlights the major physical mechanisms associated with temperature warming and HWs in the Sahel based on the spring 2010 case study. These processes include larger GHE of water vapor, more low-level moisture convergence into the western Sahel, and higher downward SWR in the southern part of the domain. In the present section, we aim at generalizing these findings on the different HWs detected over the 1979-2014 period in the western Sahel (region enclosed within the dashed box in Fig. 1). The purpose is to answer this question: Are the three important processes identified in the 2010 case study also dominating at the interannual time scale? To do so, we examine the link between HW frequency in the region of interest and the main contributors to warm anomalies identified in the AMJ10 case study over the 1979-2014 period. We consider both the total and the high-frequency variations. The HF variations are obtained after removing the linear trend from 
a) AMJ10 SH anomalies (W m-2)

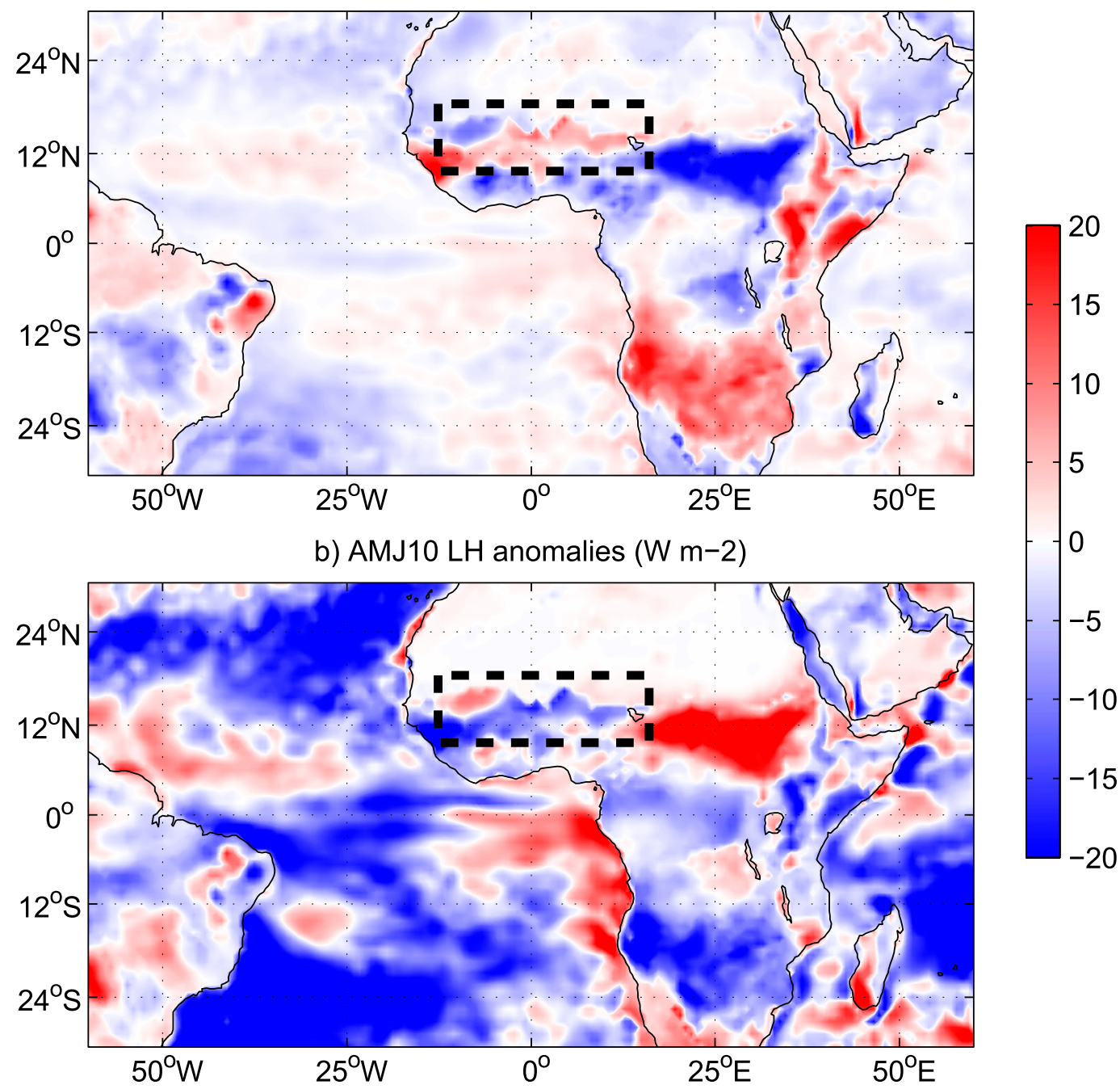

FIG. 11. AMJ10 surface (a) sensible heat flux (SH) anomalies and (b) latent heat flux (LH) anomalies. Anomalies are computed as the difference between surface fluxes during spring 2010 HW days and 1979-2014 climatology. Surface fluxes are counted negative upward. White areas are not significant at $p=0.05$ according to Student's $t$ test.

the total signal using least squares methods and correspond to the natural interannual variability. The total variations $(\mathrm{HF}+\mathrm{LF})$ include high-frequency and lowfrequency variations and account for the long-term trend and interannual variability. Figure 12 shows the 1979-2014 correlations between HW frequency and the three major contributors to spring 2010 HW: namely, the surface SWR, the GHE, and the moisture flux convergence. Table 3 shows the correlations between HW frequency, ERA-I spatially averaged Tmax and Tmin, and the different energy budget components averaged over the studied region for $\mathrm{HF}$ and $\mathrm{HF}+\mathrm{LF}$ variations. The largest positive correlations are obtained between GHE and HW frequency in the western Sahel (Fig. 12b), pointing out the role of GHE as the main driver of HWs in the region of interest. The link between HW frequency and GHE is robust across 1979-2014 period for both LF and HF variations (Table 3). During HW periods, GHE is enhanced in response to increased water vapor and LW cloud heating effect, with the former process dominating. Indeed, the water vapor feedback and the cloud warming effect explain $65 \%$ and $17 \%$ of GHE interannual variability, respectively. The remaining $18 \%$ could be attributed to the direct effect of anthropogenic GHE and should be further investigated. The larger GHE results in increased warm Tmin anomalies (as emphasized by the high correlation obtained between GHE and Tmin at both LF and HF variations; Table 3). Significant positive correlations are obtained between surface SWR and HW frequency in 
a) $r(H W$ frequency,SW)

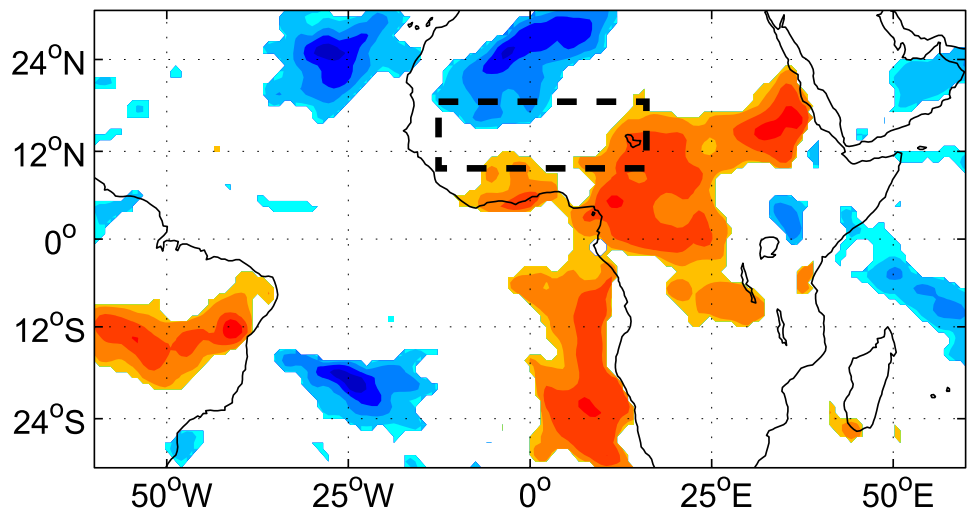

b) $r(H W$ frequency, GHE)

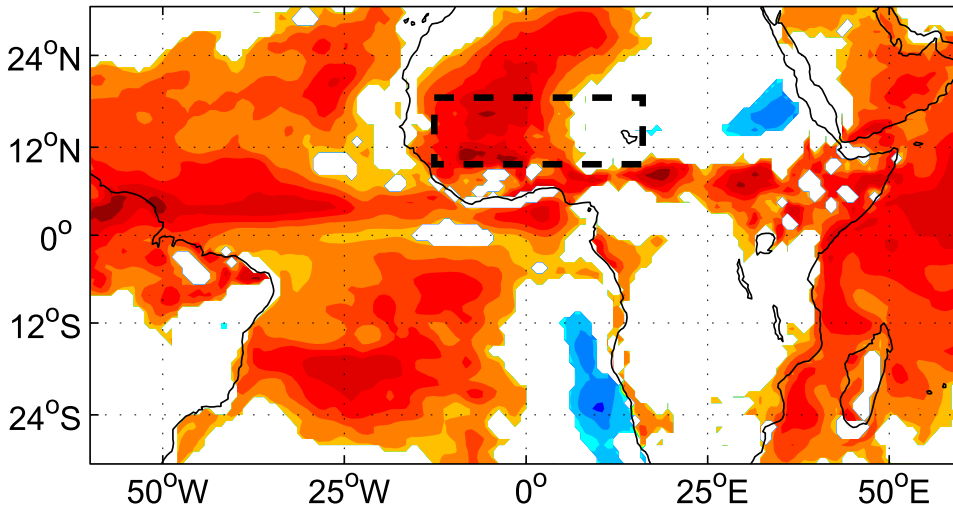

c) $r(H W$ frequency, Moisture flux convergence)

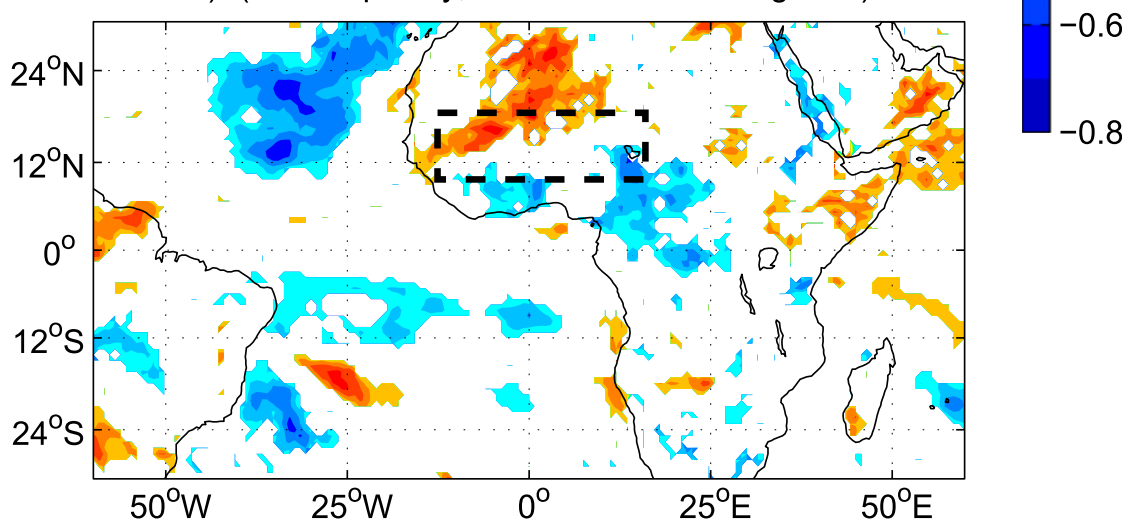

FIG. 12. Interannual correlations over 1979-2014 between HW frequency and (a) surface net SWR anomalies, (b) all-sky GHE anomalies, and (c) moisture flux convergence. White areas are not significant at $p=0.05$ according to the Bravais-Pearson test.

the southern part of the studied domain (Fig. 12a). The link between HW frequency and SWR is small but robust across the 1979-2014 period and comes mainly from the LF variations (Table 3). During HW periods, absorbed SWR is enhanced in response to reduced cloud albedo, resulting in increased warm Tmax anomalies (see the high correlation obtained between SWR and Tmax; Table 3). HWs in the western Sahel are also associated with low-level convergence of moisture flux, as shown from the obtained positive correlations over some regions of the domain that are in spatial agreement with regions of positive HW frequency-GHE correlations (Fig. 12c). This underlines the importance of horizontal winds in advecting water vapor from the tropical Atlantic Ocean and Guinean coasts into the western Sahel at interannual time scale (Table 3), sustaining the 
TABLE 3. The 1979-2014 correlations between HW frequency, Tmax, Tmin, and the different contributors to temperature anomalies during HW events averaged over the studied region, computed for the HF+LF and the HF (computed by removing the linear trend) variations. Values in bold indicate significant correlations at the $95 \%$ level according to the Bravais-Pearson test. An asterisk $(*)$ indicates significance at the $90 \%$ level.

\begin{tabular}{|c|c|c|c|c|c|c|}
\hline & \multicolumn{2}{|c|}{ HW frequency } & \multicolumn{2}{|c|}{ Tmax } & \multicolumn{2}{|c|}{ Tmin } \\
\hline & $\mathrm{HF}+\mathrm{LF}$ & $\mathrm{HF}$ & $\mathrm{HF}+\mathrm{LF}$ & $\mathrm{HF}$ & $\mathrm{HF}+\mathrm{LF}$ & $\mathrm{HF}$ \\
\hline SWR & $0.27 *$ & 0.1 & 0.78 & 0.75 & 0.51 & $0.29 *$ \\
\hline GHE & 0.62 & 0.52 & 0.18 & 0.03 & 0.6 & 0.54 \\
\hline$-\int_{0}^{p_{s}} \nabla \cdot(q v) \frac{d p}{g}$ & 0.32 & 0.24 & 0.09 & 0.03 & 0.25 & 0.09 \\
\hline $\mathrm{SH}$ & -0.31 & -0.33 & -0.51 & -0.58 & -0.4 & -0.47 \\
\hline LH & 0.05 & 0.2 & 0.37 & 0.65 & 0.07 & 0.35 \\
\hline
\end{tabular}

GHE enhancement and forcing warm Tmin anomalies. A multiple linear regression of HW frequency on the different contributors to HWs is performed and shows that $55 \%$ of the interannual variability of HWs are explained by this regression model, with $40 \%, 6 \%$, and $9 \%$ accounted for by the GHE, the SWR, and the moisture flux convergence, respectively.

\section{b. The role of large-scale conditions in the occurrence of $H W s$}

Interannual variability of temperature in West Africa in the spring season is affected by the large-scale climatic conditions associated with the delayed impact of ENSO, with anomalous warming (cooling) following warm (cold) ENSO events (Moron et al. 2016). This is also highlighted for spring HWs in the western Sahel by computing the spatial correlations between HW frequency (for GSOD and ERA-I) and DJF sea surface temperature from the Hadley Centre Sea Ice and Sea Surface Temperature dataset (HadISST) (Rayner et al. 2003) at the HF+LF and HF scales (Fig. 13). Significant positive correlations are obtained in the equatorial tropical Pacific, which are stronger at the HF scales, suggesting the important role of ENSO in HF variations of HWs, with warm ENSO events tending to amplify HW occurrence. At LF+HF scales, positive correlations are obtained over the Indian and tropical Atlantic Oceans that are mainly related to the warming trend and could be at least associated with global warming (Moron et al. 2016). Correlations in ERA-I are in spatial agreement with GSOD. However, they are overestimated over the tropical Pacific at both $\mathrm{LF}+\mathrm{HF}$ and $\mathrm{HF}$ scales, indicating that the response of HWs to ENSO is overestimated in ERA-I (Fig. 13), which explains, in particular, the overestimation of HW frequency during El Niño events in 1998 and 2010 (Fig. 4a).
To identify the physical processes driven by ENSO that are responsible for HW occurrence in the western Sahel, we examine the link between ENSO variability [estimated from the December/January multivariate ENSO index (MEI); Wolter and Timlin 1993] and the main contributors to warm anomalies at the interannual time scale. Figure 14 shows the 1979-2014 spatial correlations between the MEI and the three major contributors to HWs in the western Sahel: namely, the SWR, the GHE, and the moisture flux convergence. The largest positive correlations are obtained for the GHE over the region of interest and over the tropical North Atlantic Ocean (Fig. 14b), suggesting that the GHE is the main physical process affected by ENSO and the principal driver of HWs in the western Sahel during ENSO events (as highlighted by the significant correlation obtained between GHE and HW frequency at HF scales; Table 3). During El Niño, in response to tropospheric warming, atmospheric water holding capability increases over the tropical North Atlantic Ocean, resulting in higher water vapor amount and greater GHE. The anomalous precipitable water is advected to the western Sahel by increased horizontal convergence (Fig. 14c) and contributes to enhancing GHE locally and increasing temperature positive anomalies in the region of interest. SWR does not contribute to increasing warm temperature anomalies at HF scales (Fig. 14a). In conclusion, warm ENSO events favor warm Tmin anomalies and enhanced HW frequency in the western Sahel by amplifying the water vapor feedback and increasing downward LWR at the surface. This physical process has already been emphasized to explain the response of surface temperature in the northern United States to warm ENSO events (Zhang et al. 2011). The relationship between ENSO and HW variability in the western Sahel offers a source of predictability a few months before an extreme event. However, a robust prediction depends on the reliability of models in representing the physical processes associated with temperature response to ENSO, and particularly in representing the water vapor GHE.

\section{Summary and conclusions}

The purpose of this study is to enlarge our knowledge of HWs in the western Sahel from synoptic observations (GSOD) and reanalysis (ERA-I), document their characteristics, and identify their main physical drivers.

HWs are defined as a spell of at least 3 consecutive days with heat index of the day HImax and of the night HImin exceeding the local 90th percentile computed on all days of the control period (1981-2010). HWs are localized and occur predominantly in boreal spring (April through June), when thermal conditions are already 

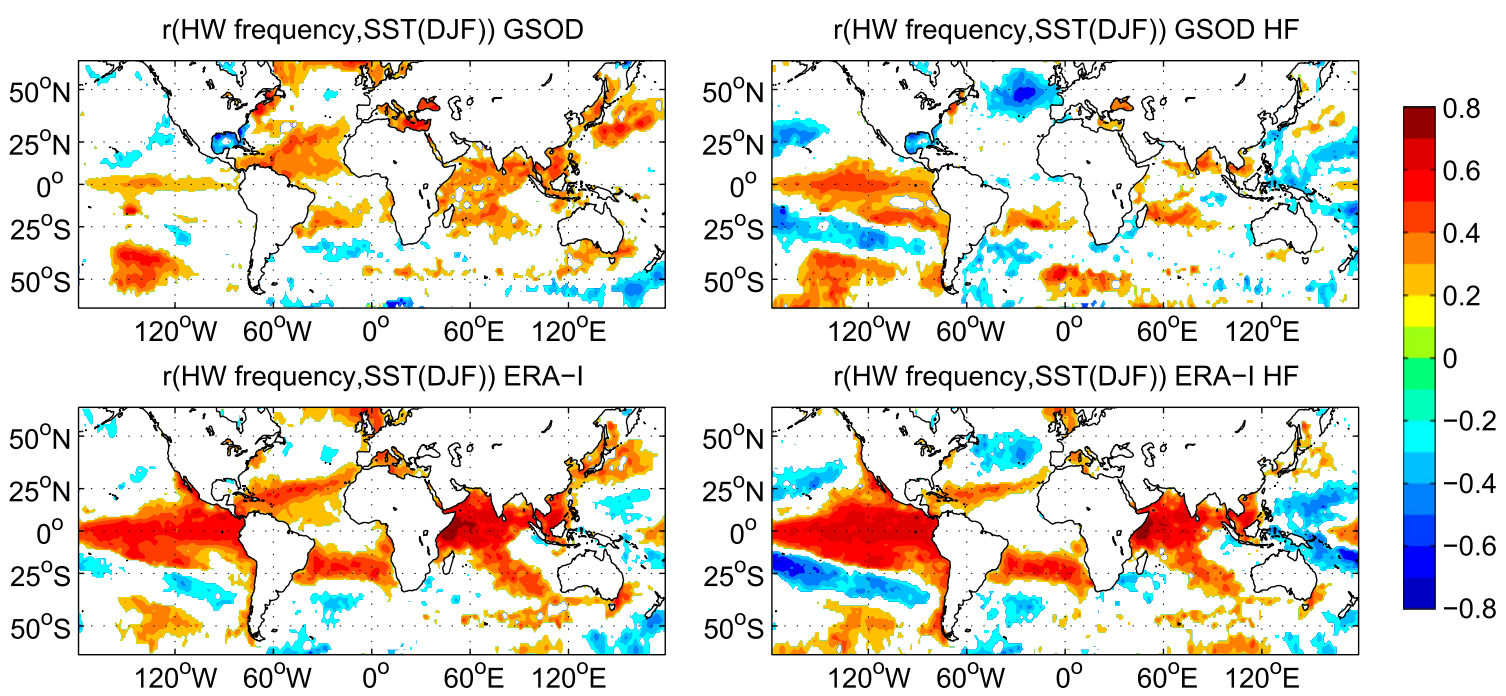

FIG. 13. Interannual correlations over 1979-2014 between spring HW frequency and the worldwide DJF surface temperature anomalies computed for (left) the HF+LF and the HF (computed by removing the linear trend) variations for (top) GSOD and (bottom) ERA-I. White areas are not significant at $p=0.05$ according to the Bravais-Pearson test.

critical for human health. HW frequency shows a significant increase over 1979-2014, in agreement with Fontaine et al. (2013) and Moron et al. (2016), with a linear trend equal to 1.21 days decade $^{-1}$ in GSOD. The year 2010 shows the largest mean number of HW days over the whole period equal on average to 11 days. Mean HW duration shows a positive trend equal to 0.46 days decade ${ }^{-1}$ with three important events lasting, on average, more than 6 days: 2003, 2005, and 2014. HW mean intensity (computed from HImax) in GSOD shows a significant increase of $0.6^{\circ} \mathrm{C}$ decade $^{-1}$ over the 1974-2014 period. In the majority of HW events, mean intensity exceeds $52^{\circ} \mathrm{C}$, which is a dangerous threshold on human health (Steadman 1979). Extremely dangerous levels are found in 1993, 2006, 2010, and 2013 with mean intensity larger than $54^{\circ} \mathrm{C}$. ERA-I captures reasonably well the HW characteristics, the interannual variability, and trend of HW frequency at the large scale. It is therefore reliable to investigate the key mechanisms and feedbacks associated with warm extremes in the Sahel, focusing on the spring 2010 case study and interannual variability. Three principal contributors are highlighted:

1) The GHE is the main driver of HWs in the western Sahel. It is dominated by the water vapor feedback as highlighted in Guichard et al. (2009); in response to more abundant water vapor within the atmosphere, larger LWR is radiated back to Earth's surface, contributing to minimum temperature increase. This result is in agreement with the localscale mechanism proposed by Giannini (2010) to explain surface temperature warming in the Sahel in response to anthropogenic warming as a result of increased net radiation at the surface amplified by water vapor feedback. In addition to water vapor, a small contribution to downward LWR at the surface is attributed to midlevel clouds (in agreement with Bouniol et al. 2012). At the interannual time scale, water vapor feedback and cloud warming effect explain $67 \%$ and $17 \%$ of the GHE variability. ${ }^{4}$ The water vapor feedback is amplified by warm ENSO events, favoring warm minimum temperature anomalies and enhanced HW frequency in the western Sahel.

2) Low-level moisture convergence played a crucial role in sustaining temperature warm anomalies by advecting more water vapor from the tropical Atlantic Ocean and Guinean coasts into the western Sahel. As temperature is increasing, water holding capacity of the air is increasing, further enhancing precipitable water amount within the atmosphere by favored surface evaporation over the tropical Atlantic Ocean and the Guinean coasts.

3) Incoming SWR at the surface contributed significantly to maximum temperature warming in the southern Sahel and the Guinean coasts through a reduction in cloud cover.

Some similarities in the driving mechanisms of HWs arise between the midlatitudes and the western Sahel. In both regions, the atmospheric circulation plays an

\footnotetext{
${ }^{4}$ These values are statistically significant at $p=0.05$ according to a Student's $t$ test.
} 
a) $r(M E I, S W R)$

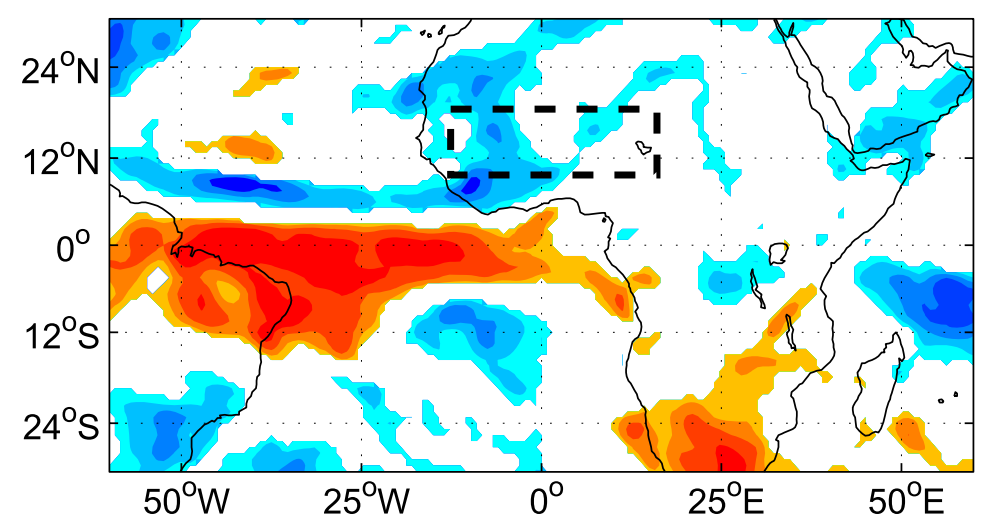

b) $r(M E I, G H E)$

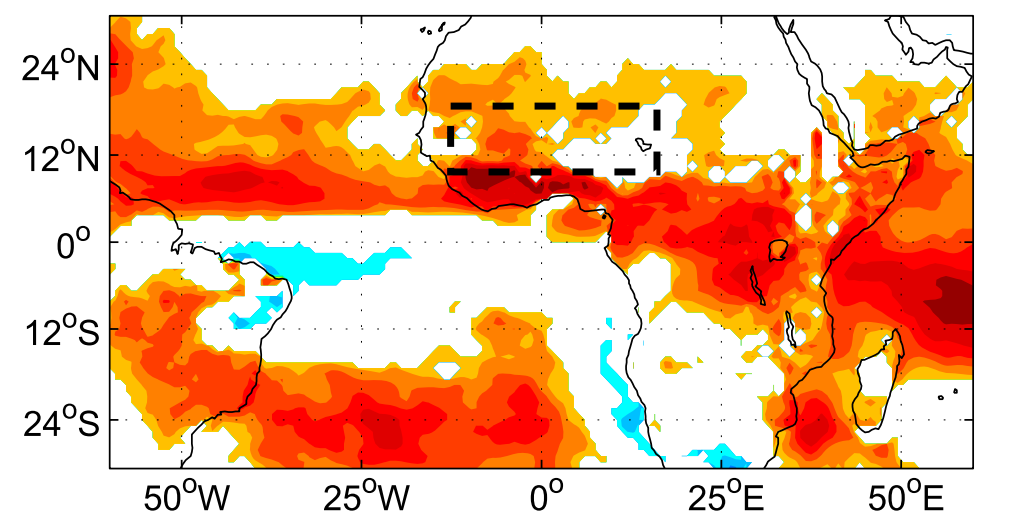

c) $r(\mathrm{MEI}$, Moisture flux convergence)

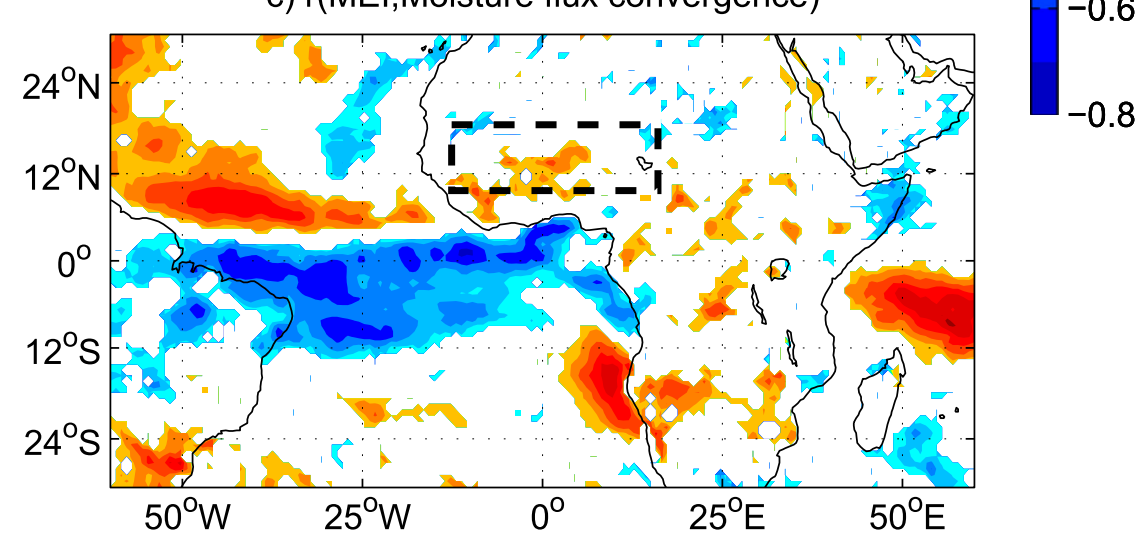

FIG. 14. Interannual correlations over 1979-2014 between the December/January MEI and AMJ10 (a) surface net SWR anomalies, (b) all-sky GHE anomalies, and (c) moisture flux convergence. White areas are not significant at $p=0.05$ according to the BravaisPearson test.

important role. In midlatitudes, atmospheric dynamics contribute directly to temperature extremes through the advection of warm air from the eastern subtropical Atlantic Ocean (Van Oldenborgh 2007; Cattiaux et al. 2009). In the western Sahel, atmospheric circulation contributes indirectly to temperature warming by advecting low-level moisture from the tropical ocean and sustaining the GHE of water vapor. Water vapor feedback is also important in midlatitudes and amplifies warm anomalies (Shongwe et al. 2011). Other local thermodynamical processes, including SW cloud radiative effect, drive further warming in midlatitudes 
a) AMJ10 Surface net SWR anomalies (W m-2) CERES-SYN1deg

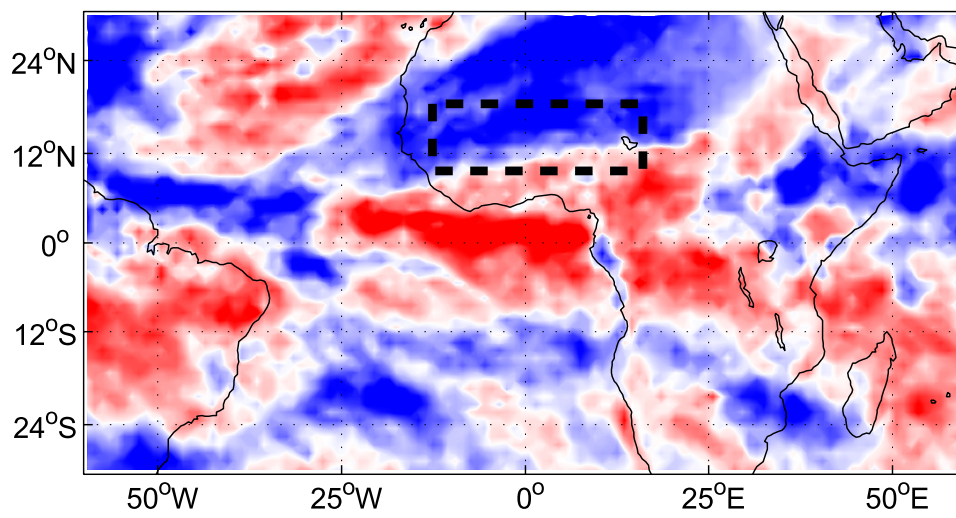

b) AMJ10 Surface net LWR anomalies (W m-2) CERES-SYN1deg

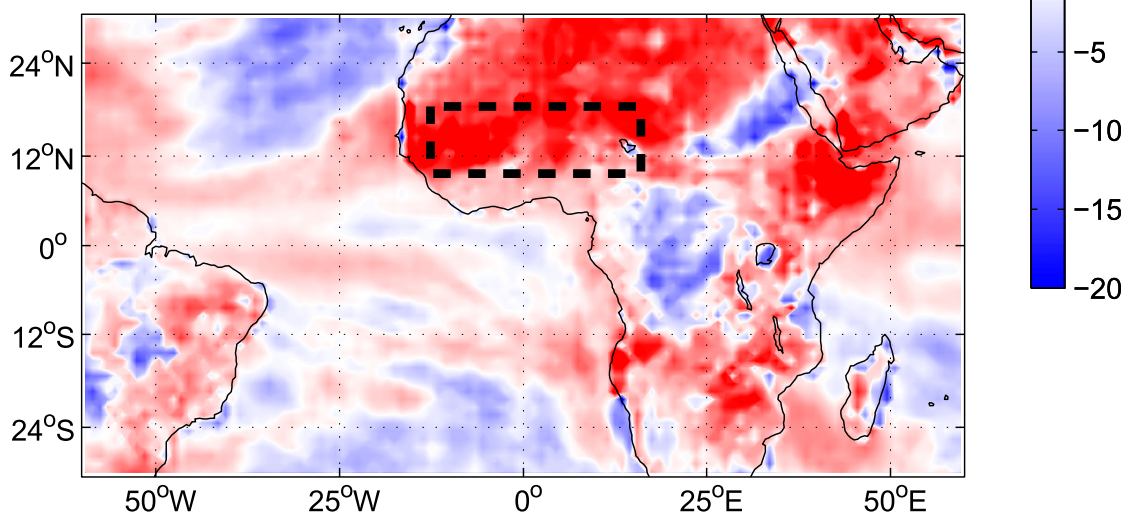

FIG. A1. AMJ10 (a) surface net SWR anomalies and (b) surface net LWR anomalies in CERES-SYN1deg. Anomalies are computed as the difference between surface fluxes during spring 2010 HW days (identified from GSOD data) and 1979-2014 climatology. Radiative fluxes are counted positive downward. Positive anomalies for both SWR and LWR represent a gain of radiative energy by the surface. White areas are not significant at $p=0.05$ according to Student's $t$ test.

(Tang et al. 2012; Boé and Terray 2014), similarly to the southern Sahel.

This study is a first step in understanding HWs in the Sahel. It shows the complexity of the associated physical mechanisms and the strong coupling between surface temperature, water vapor, and radiative fluxes. Large-scale circulation plays an important role by advecting moisture into the Sahel. Evaluating the representation of HWs and associated physical processes in climate models is essential to gain confidence in climate projections and predictions of HWs in West Africa.

Acknowledgments. This study is part of ANR project ACASIS (2014-17; Grant ANR-13-SENV-0007). Calculations were performed using HPC resources from DSI-CCUB (Université de Bourgogne). Thanks are due to Emilie Bernard for her preliminary results on HW teleconnections with remote regions.

\section{APPENDIX}

\section{Comparison of Surface Radiative Fluxes in ERA-I and CERES-SYN1deg}

ERA-I does have some problems in representing the present climate and variability because of biases in radiative fluxes (Kalnay et al. 1996; Schär and Jendritzky 2004; Bengtsson et al. 2004). It is therefore necessary to verify its quality to gain confidence in the physical processes associated with HWs. For this purpose, we carried out a comparison of surface net SWR and LWR between ERAI and the CERES-SYN1deg daily satellite product (Rutan et al. 2015) available from March 2001 to December 2014. As for ERA-I, anomalies of surface SWR and LWR are computed as the difference between surface fluxes during AMJ 2010 HW days and 1979-2014 climatology. HW days are identified based on GSOD synoptic observations. We clearly show that ERA-I patterns are in qualitative 
a) AMJ10 Surface SW CRE anomalies (W m-2) CERES-SYN1deg

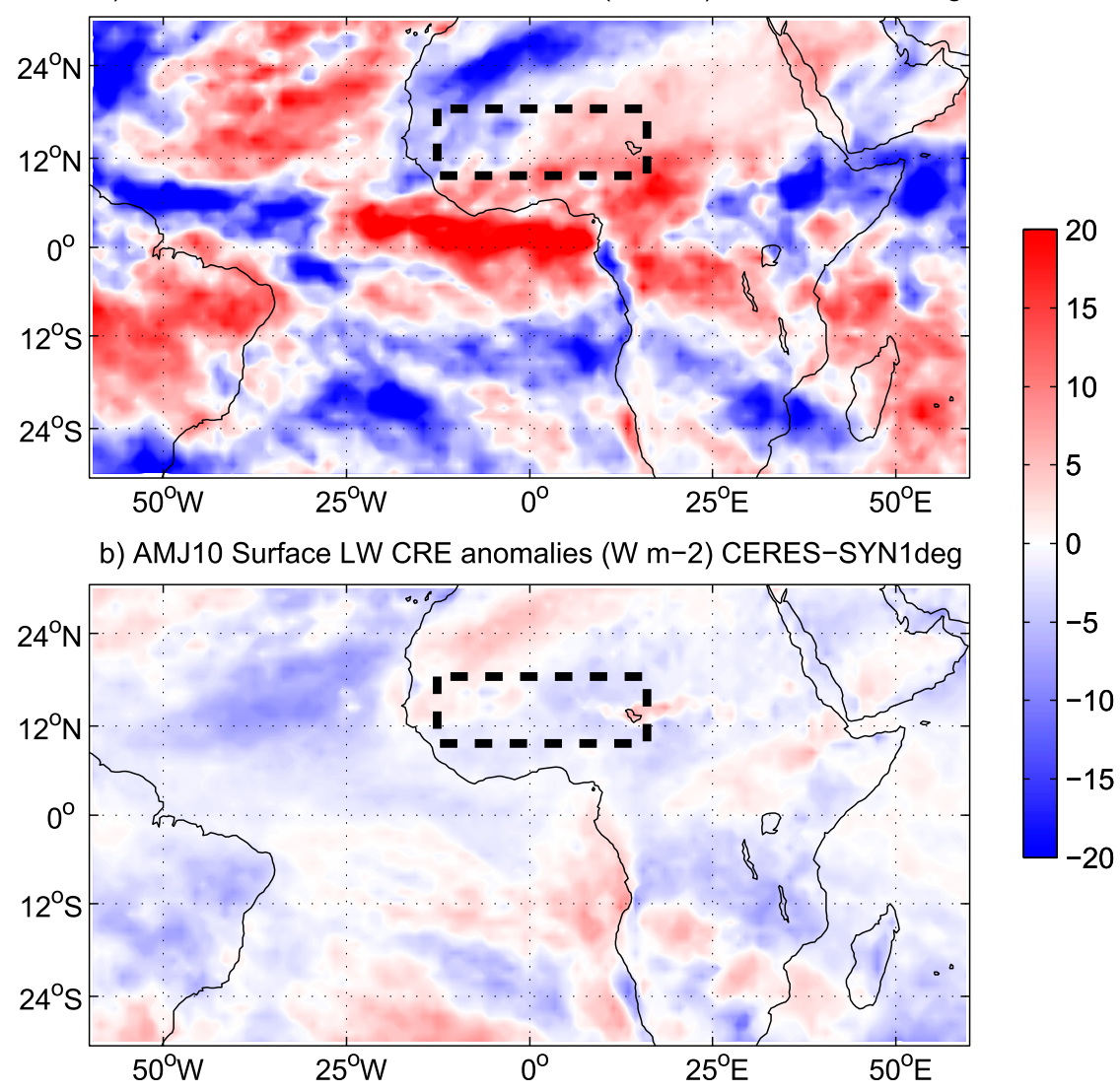

FIG. A2. AMJ10 (a) surface net SW CRE anomalies and (b) surface net LW CRE anomalies in CERES-SYN1deg. Cloud radiative effect is computed as the difference between all-sky and clear-sky surface net SWR and LWR. Anomalies are computed as the difference between CRE during spring 2010 HW days (identified from GSOD data) and 1979-2014 climatology. Positive anomalies for both SW CRE and LW CRE represent a gain of radiative energy by the surface. White areas are not significant at $p=0.05$ according to Student's $t$ test.

agreement with CERES-SYN1deg (cf. Fig. 7 and Fig. A1). Negative anomalies of surface net SWR and positive anomalies of surface LWR are diagnosed over the studied domain, indicating that downward LWR at the surface largely contributed to temperature warming in the western Sahel during AMJ 2010. The same comparison is made for the SW and LW CRE, and a qualitative agreement between the two datasets is obtained (cf. Fig. 8 and Fig. A2). ERA-I shows quantitative biases of surface fluxes as highlighted in previous studies (e.g., Wang and Dickinson 2013; Zhang et al. 2016). The reasons behind these deficiencies should be investigated but are not of the scope of the present paper.

\section{REFERENCES}

Bengtsson, L., S. Hagemann, and K. I. Hodges, 2004: Can climate trends be calculated from reanalysis data? J. Geophys. Res., 109, 839-856, doi:10.1029/2004JD004536.
Beniston, M., and Coauthors, 2007: Future extreme events in European climate: An exploration of regional climate model projections. Climatic Change, 81, 71-95, doi:10.1007/s10584-006-9226-z.

Boé, J., and L. Terray, 2014: Land-sea contrast, soil-atmosphere and cloud-temperature interactions: Interplays and roles in future summer European climate change. Climate Dyn., 42, 683-699, doi:10.1007/s00382-013-1868-8.

Bony, S., J. L. Dufresne, H. Le Treut, J. J. Morcrette, and C. Senior, 2004: On dynamic and thermodynamic components of cloud changes. Climate Dyn., 22, 71-86, doi:10.1007/s00382-003-0369-6.

Bouniol, D., F. Couvreux, P.-H. Kamsu-Tamo, M. Leplay, F. Guichard, F. Favot, and E. O'Connor, 2012: Diurnal and seasonal cycles of cloud occurrences, types, and radiative impact over West Africa. J. Appl. Meteor. Climatol., 51, 534-553, doi:10.1175/JAMC-D-11-051.1.

Cattiaux, J., R. Vautard, and P. Yiou, 2009: Origins of the extremely warm European fall in 2006. Geophys. Res. Lett., 36, L06713, doi:10.1029/2009GL037339.

Collins, M., and Coauthors, 2013: Long-term climate change: Projections, commitments and irreversibility. Climate Change 2013: The Physical Science Basis, T. F. Stocker et al., Eds., Cambridge University Press, 1029-1136. 
Dee, D. P., and Coauthors, 2011: The ERA-Interim reanalysis: Configuration and performance of the data assimilation system. Quart. J. Roy. Meteor. Soc., 137, 553-597, doi:10.1002/qj.828.

Donat, M. G., and Coauthors, 2013: Updated analyses of temperature and precipitation extreme indices since the beginning of the twentieth century: The HadEX2 dataset. J. Geophys. Res. Atmos., 118, 2098-2118, doi:10.1002/jgrd.50150.

Fischer, E. M., and C. Schär, 2009: Future changes in daily summer temperature variability: Driving processes and role for temperature extremes. Climate Dyn., 33, 917-935, doi:10.1007/ s00382-008-0473-8.

_ and _ 2010: Consistent geographical patterns of changes in high-impact European heatwaves. Nat. Geosci., 3, 398-403, doi:10.1038/ngeo866.

- S. I. Seneviratne, D. Lüthi, and C. Schär, 2007: Contribution of land-atmosphere coupling to recent European summer heat waves. Geophys. Res. Lett., 34, L06707, doi:10.1029/2006GL029068.

Fontaine, B., S. Janicot, and P.-A. Monerie, 2013: Recent changes in air temperature, heat waves occurrences and atmospheric circulation in northern Africa. J. Geophys. Res. Atmos., 118 , 536-552, doi:10.1002/jgrd.50667.

García-Herrera, R., J. Díaz, R. Trigo, J. Luterbacher, and E. Fischer, 2010: A review of the European summer heat wave of 2003. Crit. Rev. Environ. Sci. Technol., 40, 267-306, doi:10.1080/10643380802238137.

Giannini, A., 2010: Mechanisms of climate change in the semiarid African Sahel: The local view. J. Climate, 23, 743-756, doi:10.1175/ 2009JCLI3123.1.

Guichard, F., L. Kergoat, E. Mougin, F. Timouk, F. Baup, P. Hiernaux, and F. Lavenu, 2009: Surface thermodynamics and radiative budget in the Sahelian Gourma: Seasonal and diurnal cycles. J. Hydrol., 375, 161-177, doi:10.1016/j.jhydrol.2008.09.007.

Kalnay, E., and Coauthors, 1996: The NCEP/NCAR 40-Year Reanalysis Project. Bull. Amer. Meteor. Soc., 77, 437-471, doi:10.1175/1520-0477(1996)077<0437:TNYRP>2.0.CO;2.

Kharin, V. V., F. Zwiers, X. Zhang, and M. Wehner, 2013: Changes in temperature and precipitation extremes in the IPCC ensemble of global coupled model simulations. Climatic Change, 119, 345-357, doi:10.1007/s10584-013-0705-8.

Meehl, G. A., and C. Tebaldi, 2004: More intense, more frequent, and longer lasting heat waves in the 21st century. Science, $\mathbf{3 0 5}$, 994-997, doi:10.1126/science.1098704.

Moron, V., B. Oueslati, B. Pohl, S. Rome, and S. Janicot, 2016: Trends of mean temperatures and warm extremes in northern tropical Africa (1961-2014) from observed and PPCAreconstructed time series. J. Geophys. Res. Atmos., 121, 5298-5319, doi:10.1002/2015JD024303.

Rayner, N. A., D. E. Parker, E. B. Horton, C. K. Folland, L. V. Alexander, D. P. Rowell, E. C. Kent, and A. Kaplan, 2003: Global analyses of sea surface temperature, sea ice, and night marine air temperature since the late nineteenth century. J. Geophys. Res., 108, 4407, doi:10.1029/2002JD002670.

Rienecker, M. M., and Coauthors, 2011: MERRA: NASA's ModernEra Retrospective Analysis for Research and Applications. J. Climate, 24, 3624-3648, doi:10.1175/JCLI-D-11-00015.1.

Roehrig, R., D. Bouniol, F. Guichard, F. Hourdin, and J.-L. Redelsperger, 2013: The present and future of the West African monsoon: A process-oriented assessment of CMIP5 simulations along the AMMA transect. J. Climate, 26, 6471-6505, doi:10.1175/JCLI-D-12-00505.1.

Rome, S., B. Oueslati, V. Moron, B. Pohl, and A. Diedhiou, 2016: Les vagues de chaleur au Sahel: Définition et principales caractéristiques spatio-temporelles (1973-2014). XXIXe Colloque de l'Association Internationale de Climatologie, Besançon, France, AIP, 345-350.

Russo, S., A. F. Marchese, J. Sillmann, and G. Immé, 2016: When will unusual heat waves become normal in a warming Africa? Environ. Res. Lett., 11, 054016, doi:10.1088/1748-9326/11/5/054016.

Rutan, D. A., S. Kato, D. R. Doelling, F. G. Rose, L. T. Nguyen, T. E. Caldwell, and N. G. Loeb, 2015: CERES synoptic product: Methodology and validation of surface radiant flux. J. Atmos. Oceanic Technol., 32, 1121-1143, doi:10.1175/ JTECH-D-14-00165.1.

Schär, C., and G. Jendritzky, 2004: Climate change: Hot news from summer 2003. Nature, 432, 559-560, doi:10.1038/432559a.

Seneviratne, S. I., and Coauthors, 2012: Changes in climate extremes and their impacts on the natural physical environment. Managing the Risks of Extreme Events and Disasters to Advance Climate Change Adaptation, C. B. Field et al., Eds., Cambridge University Press, 109-230.

Shongwe, M. E., R. G. Graversen, G. J. van Oldenborgh, B. J. J. M. van den Hurk, and F. J. Doblas-Reyes, 2011: Energy budget of the extreme autumn 2006 in Europe. Climate Dyn., 36, 10551066, doi:10.1007/s00382-009-0689-2.

Steadman, R. G., 1979: The assessment of sultriness. Part I: A temperature-humidity index based on human physiology and clothing science. J. Appl. Meteor., 18, 861-873, doi:10.1175/ 1520-0450(1979)018<0861:TAOSPI $>2.0$.CO;2.

Tang, Q., G. Leng, and P. Y. Groisman, 2012: European hot summers associated with a reduction of cloudiness. J. Climate, 25, 3637-3644, doi:10.1175/JCLI-D-12-00040.1.

Van Oldenborgh, G., 2007: How unusual was autumn 2006 in Europe? Climate Past, 3, 659-668, doi:10.5194/cp-3-659-2007.

Vizy, E. K., and K. H. Cook, 2012: Mid-twenty-first-century changes in extreme events over northern and tropical Africa. J. Climate, 25, 5748-5767, doi:10.1175/JCLI-D-11-00693.1.

Wang, K., and R. E. Dickinson, 2013: Global atmospheric downward longwave radiation at the surface from ground-based observations, satellite retrievals, and reanalyses. Rev. Geophys., 51, 150-185, doi:10.1002/rog.20009.

Wolter, K., and M. Timlin, 1993: Monitoring ENSO in COADS with a seasonally adjusted principal component index. Proc. 17th Climate Diagnostics Workshop, Norman, OK, NOAA/ National Meteorological Center/Climate Analysis Center, 5257. [Available online at https://www.esrl.noaa.gov/psd/enso/ mei/WT1.pdf.]

Zhang, T., M. P. Hoerling, J. Perlwitz, D.-Z. Sun, and D. Murray, 2011: Physics of U.S. surface temperature response to ENSO. J. Climate, 24, 4874-4887, doi:10.1175/2011JCLI3944.1.

Zhang, X., S. Liang, G. Wang, Y. Yao, B. Jiang, and J. Cheng, 2016: Evaluation of the reanalysis surface incident shortwave radiation products from NCEP, ECMWF, GSFC, and JMA using satellite and surface observations. Remote Sens., 8, 225, doi:10.3390/rs8030225. 